\title{
Profiling and relative quantification of multiply nitrated and oxidized fatty acids
}

\author{
Ivana Milic ${ }^{1,2}$ - Eva Griesser ${ }^{1,2}$ - Venukumar Vemula ${ }^{1,2}$ - Naoya Ieda ${ }^{3}$. \\ Hidehiko Nakagawa $^{3,4}$ • Naoki Miyata ${ }^{3}$ Jean-Marie Galano ${ }^{5}$. \\ Camille Oger $^{5} \cdot$ Thierry Durand $^{5} \cdot$ Maria Fedorova $^{1,2}$
}

Received: 13 March 2015 / Revised: 30 April 2015 / Accepted: 5 May 2015

(C) Springer-Verlag Berlin Heidelberg 2015

\begin{abstract}
The levels of nitro fatty acids $\left(\mathrm{NO}_{2}-\mathrm{FA}\right)$, such as nitroarachidonic, nitrolinoleic, nitrooleic, and dinitrooleic acids, are elevated under various inflammatory conditions, and this results in different anti-inflammatory effects. However, other multiply nitrated and nitro-oxidized FAs have not been studied so far. Owing to the low concentrations in vivo, $\mathrm{NO}_{2}$-FA analytics usually relies on targeted gas chromatography-tandem mass spectrometry (MS/MS) or liquid chromatography-MS/MS, and thus require standard compounds for method development. To overcome this limitation and increase the number and diversity of analytes, we performed in-depth mass spectrometry (MS) profiling of nitration products formed in vitro by incubating fatty acids with $\mathrm{NO}_{2} \mathrm{BF}_{4}$, and $\mathrm{ONOO}^{-}$. The modified fatty acids were used to develop a highly specific and sensitive multiple reaction
\end{abstract}

Electronic supplementary material The online version of this article (doi:10.1007/s00216-015-8766-3) contains supplementary material, which is available to authorized users.

Maria Fedorova

maria.fedorova@bbz.uni-leipzig.de

1 Faculty of Chemistry and Mineralogy, Institute of Bioanalytical Chemistry, Leipzig, Germany

2 Center for Biotechnology and Biomedicine, Universität Leipzig, Deutscher Platz 5, 04103 Leipzig, Germany

3 Graduate School of Pharmaceutical Science, Nagoya City University, 3-1, Tanabe-dori, Mizuho-ku, Nagoya, Aichi 467-8603, Japan

4 PRESTO, Japan Science and Technology Agency, 4-1-8 Honcho, Kawaguchi, Saitama 332-0012, Japan

5 Institut des Biomolécules Max Mousseron, Université de Montpellier, ENSCM, CNRS UMR 5247, Montpellier, France monitoring LC-MS method for relative quantification of 42 different nitrated and oxidized species representing three different groups: singly nitrated, multiply nitrated, and nitro-oxidized fatty acids. The method was validated in in vitro nitration kinetic studies and in a cellular model of nitrosative stress. $\mathrm{NO}_{2}$-FA were quantified in lipid extracts from 3-morpholinosydnonimine-treated rat primary cardiomyocytes after 15, 30, and $70 \mathrm{~min}$ from stress onset. The relatively high levels of dinitrooleic, nitroarachidonic, hydroxynitrodocosapenataenoic, nitrodocosahexaenoic, hydroxynitrodocosahexaenoic, and dinitrodocosahexaenoic acids confirm the presence of multiply nitrated and nitro-oxidized fatty acids in biological systems for the first time. Thus, in vitro nitration was successfully used to establish a targeted LC-MS/MS method that was applied to complex biological samples for quantifying diverse $\mathrm{NO}_{2}$-FA.

Keywords Cardiomyocytes $\cdot$ Lipid nitration $\cdot$ Lipid peroxidation $\cdot$ Nitrated fatty acids $\cdot$ Nitrosative stress

\section{Introduction}

Nitric oxide $(\cdot \mathrm{NO})$ is a well-known mediator of various biological processes [1]. Besides being a potent vasodilator, $\bullet \mathrm{NO}$ is generated by phagocytes as part of the innate immune response [2] preventing platelet aggregation [3, 4] and leukocyte adhesion to the endothelium [5]. Under aerobic conditions, nitric oxide readily reacts with reactive oxygen species (ROS) yielding various reactive nitrogen species (RNS) [6]. Whereas some RNS can act as oxidants and nitrosylating agents $\left(\mathrm{NO}^{+}, \mathrm{N}_{2} \mathrm{O}_{3}\right.$, etc.), nitrogen dioxide radical $\left(\cdot \mathrm{NO}_{2}\right)$, peroxynitrite anion $\left(\mathrm{ONOO}^{-}\right)$, and nitronium cation $\left(\mathrm{NO}_{2}{ }^{+}\right)$ are known nitrating species. The concentrations of $\bullet \mathrm{NO}$ and 
oxygen in the hydrophobic environment of cellular membranes and the lipid core of lipoproteins can be several times higher than in the cytoplasm, triggering elevated RNS production rates. In fact, around $90 \%$ of $\bullet \mathrm{NO}$ is auto-oxidized in these compartments $[7,8]$ and this can modify surrounding biomolecules. Free polyunsaturated fatty acids (PUFA) and their esters are the primary targets of RNS owing to their high susceptibility to oxidation and nitration.

In vivo formation of nitrated fatty acids $\left(\mathrm{NO}_{2}-\mathrm{FA}\right)$ was supported by their detection in human blood plasma [9-13], membranes of red blood cells [14], and urine [15, 16]. Recent evidence indicates increased nitroalkene production rates in various inflammatory models, such as a 20 -fold higher cholesteryl nitrolinoleate level in murine J774.1 macrophages activated by an inflammatory stimulus [17]. Increased levels of nitrolinoleic acid $\left(\mathrm{LaNO}_{2}\right)$ were detected in mitochondria during ischemic preconditioning, whereas the level of nitrooleic acid $\left(\mathrm{OaNO}_{2}\right)$ remained unchanged, indicating possible selectivity of fatty acid nitration [18]. Under inflammatory conditions $\mathrm{LaNO}_{2}, \mathrm{OaNO}_{2}$, and nitroarachidonic acid $\left(\mathrm{AaNO}_{2}\right)$ posses anti-inflammatory activities [19-21], including activation of peroxisome-proliferator-activated receptors [22] and nuclear factor E2 related factor 2 [23, 24], induction of heme oxygenase 1 [25], inhibition of nuclear factor $\mathrm{kB}$, and inhibition of prostaglandin endoperoxide $\mathrm{H}$ synthase (PGHS) [26] and NADPH oxidase [27]. $\mathrm{OaNO}_{2}$ decreased superoxide production in activated macrophages and pulmonary artery smooth muscle cells, demonstrating protective effects in a hypoxia-induced murine model of pulmonary hypertension [28]. Additionally, $\mathrm{OaNO}_{2}$ reduced atherosclerotic lesion formation in apolipoprotein $\mathrm{E}$ deficient mice by inhibiting vascular smooth muscle cell proliferation [29]. Recently it was demonstrated that $\mathrm{OaNO}_{2}$ effectively induces expression of heat shock proteins and antioxidant enzymes in keratinocytes [30]. Synthetic $\mathrm{AaNO}_{2}$ revealed several new regulatory properties in cellular models that might be common for $\mathrm{NO}_{2}$-FA. Release of nitric oxide by $\mathrm{AaNO}_{2}$ can induce cyclic GMP (cGMP)-dependent vasorelaxation and downregulate inducible nitric oxide synthase [31]. Additionally, $\mathrm{AaNO}_{2}$ was shown to prevent NADPH oxidase assembly [27], regulate protein kinase $\mathrm{C}$ [32], and inhibit oxygenase activities of PGHS-1 and PGHS-2.

Despite increasing interest in the therapeutic potential of $\mathrm{NO}_{2}$-FA, their in vivo diversity has not been fully discovered. Currently, data are limited to $\mathrm{LaNO}_{2}, \mathrm{OaNO}_{2}$, and $\mathrm{AaNO}_{2}$, whereas other possible modifications-for example, polynitro-PUFA and hydroxynitro-PUFA - have rarely been addressed. In vivo, ROS and RNS are produced simultaneously, and it is likely that oxidation of PUFA can be followed by their nitration, and vice versa, leading to a higher diversity of modified PUFA than is currently assumed. Owing to their very low in vivo concentrations, ranging from high picomolar to low nanomolar concentrations, mass-spectrometric detection of $\mathrm{NO}_{2}$-FA is very challenging. Therefore, multiple reaction monitoring (MRM) is often used to achieve the required sensitivity. However, MRM allows only targeted detection, and is thus limited to known or expected compounds. It does not provide information on $\mathrm{NO}_{2}$-FA diversity. To overcome these limitations, we performed an in-depth profiling of PUFA [oleic acid (Oa), linoleic acid (La), conjugated La (cLa), arachidonic acid (Aa), and docosahexaenoic acid (Dha)] nitrated in vitro under low and high oxygen tension to monitor the kinetics of $\mathrm{NO}_{2}$-FA. On the basis of the diversity of $\mathrm{NO}_{2}$-FA identified in vitro, a highly specific and sensitive liquid chromatography (LC)-tandem mass spectrometry (MS/MS) MRM method was developed and applied for the detection and relative quantification of $\mathrm{NO}_{2}$-FA in a cardiomyocyte cell model of nitrosative stress.

\section{Materials and methods}

\section{Chemicals}

All unsaturated fatty acids, tert-butyl methyl ether (MTBE), lithium trifluoroacetate, and horse serum were purchased from Sigma-Aldrich (Taufkirchen, Germany). Acetonitrile, methanol, and ammonium formate [ultrapure LC/mass spectrometry (MS) grade] were obtained from Biosolve (Valkenswaard, Netherlands). Chloroform was purchased from Merck (Darmstadt, Germany). 2,3,5,6-Tetramethyl4-(methylnitrosoamino)phenol (P-NAP) was synthesized according to Ieda et al. [33]. $\mathrm{C}_{21}-15-\mathrm{F}_{2 \mathrm{t}}-\mathrm{IsoP}, d_{4}-10-\mathrm{F}_{4 \mathrm{t}} \mathrm{-NeuroP}$, and $d_{4}-4-\mathrm{RS}-4-\mathrm{F}_{4 \mathrm{t}}$-NeuroP were synthesized according to the published procedure [34, 35]. Dulbecco's modified Eagle's medium/Ham's F12 medium was purchased from PAA Laboratories (Cölbe, Germany). Fetal bovine serum, phosphate-buffered saline, L-glutamine, nonessential amino acids, sodium pyruvate, and antibiotic (penicillin/streptomycin) solutions were obtained from Life Technologies (Darmstadt, Germany). 3-Morpholinosydnonimine (SIN-1) was purchased from Enzo Life Sciences (Lörrach, Germany).

\section{PUFA nitration by $\mathrm{NO}_{2} \mathrm{BF}_{4}$}

Oa, La, Aa, and Dha (100 g/L in chloroform) were nitrated in the presence of solid nitronium tetrafluoroborate $\left(\mathrm{NO}_{2} \mathrm{BF}_{4}\right.$; $100 \mathrm{mg}$, PUFA- $\mathrm{NO}_{2} \mathrm{BF}_{4}, 1: 2$ molar ratio, $20^{\circ} \mathrm{C}, 1 \mathrm{~h}$, intense shaking). Nitration was quenched $(0.5 \mathrm{~mL}$ of deionized water; vortexing for $30 \mathrm{~s}$ ), and the lower organic phase was dried under a vacuum and reconstituted in chloroform $(1 \mathrm{~mL})$. Vials were sealed with Teflon caps and purged with nitrogen gas prior to storage at $-20{ }^{\circ} \mathrm{C}$. The kinetics of nitration was recorded for $2 \mathrm{~h}$ by taking aliquots $(100 \mu \mathrm{L}) 0.5,15,30,45$, 60, 90, and $120 \mathrm{~min}$ after addition of the nitrating reagent. Samples were analyzed immediately. 


\section{Nitration of cLa by P-NAP}

An aliquot of cLa $(75 \mu \mathrm{L} ; 8 \mathrm{mmol} / \mathrm{L})$ was co-incubated with the photocontrollable peroxynitrite donor P-NAP $(24 \mu \mathrm{L}$, $100 \mathrm{mmol} / \mathrm{L}$ in dimethylformamide) [33]. The open polypropylene tube containing the sample was placed under a UV lamp (Dr. Hönle, Gräfelfing, Germany) and irradiated (20 min) with monochromatic UV-A light $(350 \mathrm{~nm})$ with an average flux of $105 \mathrm{~W} / \mathrm{m}^{2}$. The kinetics of nitration was recorded for $2 \mathrm{~h}$ by taking aliquots $(50 \mu \mathrm{L}) 0,3,6,9,15,30,60$, and $120 \mathrm{~min}$ after the reaction had started. Nitrated cLa was extracted using chloroform $(100 \mu \mathrm{L})$, dried, and reconstituted in chloroform $(50 \mu \mathrm{L})$. Samples were analyzed immediately.

\section{Electrospray ionization LTQ Orbitrap MS of nitrated PUFA}

Samples were diluted in a mixture of methanol and chloroform $(2: 1, \mathrm{v} / \mathrm{v})$ containing ammonium formate $(5 \mathrm{mmol} / \mathrm{L})$ to obtain $10 \mu \mathrm{mol} / \mathrm{L}$ solutions [used for negative ion mode electrospray ionization (ESI) MS] or in a $5 \mathrm{mmol} / \mathrm{L}$ solution of lithium trifluoroacetate in methanol (positive ion mode ESI-MS). The samples were analyzed using a robotic nanoflow ion source (TriVersaNanoMate; AdvionBioSciences, Ithaca, NY, ZSA) equipped with a nanoelectrospray chip (-1.2-kV ionization voltage, 0.3-psi nitrogen backpressure for negative ion mode; 1.4-kV ionization voltage, 0.4 -psi nitrogen backpressure for positive ion mode) coupled to an LTQ Orbitrap XL ETD mass spectrometer (Thermo Fischer Scientific, Bremen, Germany). The temperature of the transfer capillary was set to $200{ }^{\circ} \mathrm{C}$ and the tube lens voltage was set to $120 \mathrm{~V}$. Mass spectra were acquired with the Orbitrap with a target mass resolution of 100,000 at $\mathrm{m} / \mathrm{z} 400$. Collisioninduced dissociation (CID) and higher-energy CID (HCD) relied on an isolation width of $1.5 u$ and a normalized collision energy of $30 \%$ (CID) and $42 \%$ (HCD). Recorded data were analyzed manually using Xcalibur (version 2.0.7, Thermo Fisher).

\section{PUFA nitration kinetics using MRM}

Analyses were performed with as ESI 4000 QTRAP system (AB Sciex Germany, Darmstadt, Germany) operated in a negative ion mode with an ionization voltage of $-4.5 \mathrm{kV}$, an entrance potential of $-10 \mathrm{~V}$, and an ion source temperature of $600{ }^{\circ} \mathrm{C}$. The normalized collision energy, declustering potential, and exit quadrupole potential were optimized for each Q1/Q3 transition. The MRM included the two most intense transitions of each analyte with a dwell time of $40 \mathrm{~ms}$. Each sample $(30 \mu \mathrm{L}$ in ESI solution) was infused with methanol $(0.2 \mathrm{~mL} / \mathrm{min})$ using an Waters Alliance 2790 highperformance LC instrument (Waters, Eschborn, Germany) and measured in triplicate. Data were processed using Analyst (version 1.6, AB Sciex).

\section{Analytical characterization of nitrated and oxidized PUFA in cardiomyocytes}

In vitro nitration mixtures of $\mathrm{Oa}, \mathrm{La}, \mathrm{Aa}$, Dha, and cLa were used to determine the retention times of all products. The LCMRM was performed with a nanoACQUITY UPLC system (Waters, Eschborn, Germany) operated in high flow mode using the mixer kit for $1 \mathrm{~mm}$ columns (Waters, Eschborn, Germany) coupled to an ESI triple-quadrupole linear ion trap MS instrument (4000 QTRAP, AB Sciex Germany, Darmstadt, Germany). Samples were separated on an ACQUITY UPLC HSS T3 $\mathrm{C}_{18}$ column (internal diameter $1 \mathrm{~mm}$, length $100 \mathrm{~mm}$, pore size $100 \AA$, and particle size $1.8 \mu \mathrm{m}$ ) using a column temperature of $50^{\circ} \mathrm{C}$, a flow rate of $100 \mu \mathrm{L} / \mathrm{min}$, and a linear 6-minute gradient from $30 \%$ acetonitrile to $98 \%$ acetonitrile in $0.1 \%$ aqueous $\mathrm{HCOOH}$. The electrospray voltage was set to $-4.5 \mathrm{kV}$, the ion source temperature was set to $600^{\circ} \mathrm{C}$, the entrance potential was set to $-10 \mathrm{~V}$, and the dwell time was set to $40 \mathrm{~ms}$. All previously optimized transition pairs (declustering potential, collision energy, and exit quadrupole potential) of each analyte were included to record their retention times (see Table S1), whereas only the most sensitive and retention-time-specific transitions of each analyte were included in the final MRM method used for the relative quantification of nitrated and oxidized PUFA in the cardiomyocyte nitrosative stress model.

\section{Cardiomyocyte cell culture and nitrosative stress induction}

Primary rat cardiomyocytes (Innoprot, Elexalde Derio, Spain) were cultured until $80 \%$ confluence in Dulbecco's modified Eagle's medium/Ham's F12 medium supplemented with fetal bovine serum $(20 \%)$, horse serum (5\%), L-glutamine ( $2 \mathrm{mmol} / \mathrm{L})$, nonessential amino acids $(0.1 \mathrm{mmol} / \mathrm{L})$, sodium pyruvate $(3 \mathrm{mmol} / \mathrm{L})$, and antibiotics $(1 \%)$ at $37^{\circ} \mathrm{C}(95 \%$ air and $5 \% \mathrm{CO}_{2}$ atmosphere). The medium was replaced with serum-free medium $24 \mathrm{~h}$ before treatment with 3morpholinosydnonimine (SIN-1; $10 \mu \mathrm{mol} / \mathrm{L}, 15,30$, and $70 \mathrm{~min}$ ). Untreated (control) and treated cells (around $1.5 \times$ $10^{6}$ ) were collected and washed with phosphate-buffered saline ( $\mathrm{pH}$ 7.4), and lipids were extracted using MTBE [36]. Briefly, cell pellets were resuspended in $50 \mu \mathrm{L}$ of ice-cold $0.1 \%$ aqueous ammonium acetate containing $1 \mathrm{ng}$ of internal standards $\left(\mathrm{C}_{21}-15-\mathrm{F}_{2 \mathrm{t}^{-}}\right.$IsoP, $d_{4}-10-\mathrm{F}_{4 \mathrm{t}}-\mathrm{NeuroP}, d_{4}-4-\mathrm{RS}-4-\mathrm{F}_{4 \mathrm{t}^{-}}$ NeuroP; Table S1). After 15 min on ice, $375 \mu \mathrm{L}$ of methanol and $1.25 \mathrm{~mL}$ of MTBE were added, and the mixture was kept on a rotary shaker for $1 \mathrm{~h}$ at $4{ }^{\circ} \mathrm{C}$. Separation of phases was achieved by adding water $(313 \mu \mathrm{L})$ and keeping the mixture 
on the rotary shaker for $10 \mathrm{~min}$ at $4{ }^{\circ} \mathrm{C}$. After centrifugation $\left(5 \mathrm{~min}, 4^{\circ} \mathrm{C}, 1,000 \mathrm{~g}\right.$ ) the upper, organic phase was collected and dried under a vacuum. The lower, aqueous phase was used to measure the protein concentration by a Bradford assay. Data were acquired and analyzed using Analyst (version 1.6).

\section{Results and discussion}

\section{Mass-spectrometric analysis of fatty acids nitrated with $\mathrm{NO}_{2} \mathrm{BF}_{4}$}

Nitronium tetrafluoroborate $\left(\mathrm{NO}_{2} \mathrm{BF}_{4}\right)$ readily produces $\mathrm{NO}_{2}{ }^{+}$, which can nitrate PUFA by electrophilic substitution. Although nitration of fatty acids by $\mathrm{NO}_{2} \mathrm{BF}_{4}$ results in an array of different nitration products and not just a few positional nitration isomers, we used this approach because of its simplicity and the relatively high yields of nitrated PUFA. After $1 \mathrm{~h}$ nitration of $\mathrm{Oa}, \mathrm{La}, \mathrm{Aa}$, and $\mathrm{Dha}$, the sample mixtures were directly analyzed by ESI LTQ Orbitrap MS. The high resolution (HR) and mass accuracy provided elemental compositions of the detected nitration products (Table 1), including singly or multiply nitrated derivatives and nitro-oxidized species (Fig. 1). Fluorinated $\mathrm{NO}_{2}$-FA, which were also observed as by-products, were not considered in the following study.

Nitration of Oa yielded ten signals corresponding to different reaction products of Oa (Fig. 1a). The signal of deprotonated $\mathrm{Oa}(\mathrm{m} / \mathrm{z} 281.25)$ was not observed, indicating that within $1 \mathrm{~h}$ of nitration, Oa was quantitatively consumed. Two low-intensity signals at $\mathrm{m} / \mathrm{z} 295.23$ and $\mathrm{m} / \mathrm{z} 297.24$ were assigned as keto-Oa $(\mathrm{OaO})$ and hydroxy-Oa $(\mathrm{OaOH})$, whereas the remaining eight signals, including the base peak, corresponded to nitrated or nitroslyated Oa. Detection of $\mathrm{OaNO}_{2}\left(\mathrm{~m} / z\right.$ 326.23), dinitro-Oa $\left[\mathrm{Oa}\left(\mathrm{NO}_{2}\right)_{2} ; m / z\right.$ 371.22], and trinitro-Oa $\left[\mathrm{Oa}\left(\mathrm{NO}_{2}\right)_{3} ; \mathrm{m} / \mathrm{z} 416.20\right]$ showed that up to three $\mathrm{NO}_{2}$ groups can be present although Oa contains only one double bond. Although electrophilic nitration is known to produce vinylnitro isomers, detection of $\mathrm{Oa}\left(\mathrm{NO}_{2}\right)_{3}$ after $\mathrm{Oa}$ nitration suggests the presence of allylic $\mathrm{NO}_{2}$ groups. Signals with a mass shift of $+29.99 \mathrm{u}$ were assigned to nitroso-Oa (OaNO; $m / z$ 310.24) and nitrosodinitro-Oa $\left[\mathrm{Oa}\left(\mathrm{NO}_{2}\right)_{2} \mathrm{NO}\right.$, $\mathrm{m} / \mathrm{z}$ 398.19]. The signal at $\mathrm{m} / \mathrm{z} 342.23$ may indicate hydroxynitro-Oa $\left(\mathrm{OaNO}_{2} \mathrm{OH}\right)$, an oxidized nitro species. Peaks corresponding to nitrooctadecadienoic acid $\left[\mathrm{La}\left(\mathrm{NO}_{2}\right)_{2}, \mathrm{~m} / z\right.$ 369.20] and nitrosonitrooctadecadienoic acid $\left(\mathrm{LaNO}_{2} \mathrm{NO} ; \mathrm{m} / \mathrm{z} 353.21\right)$ showed that $\mathrm{Oa}$ nitration can yield products containing two double bonds, such as octadecadienoic acid.

La nitration resulted in nine reaction products (Fig. 1b), including oxidized forms, such as keto- $\mathrm{La}(\mathrm{LaO} ; \mathrm{m} / \mathrm{z}$ 293.21) and hydroxy-La (LaOH; $m / z$ 295.23). Notably, signals of the oxidized La were more intense then the signals of oxidized Oa species. The peak corresponding to deprotonated

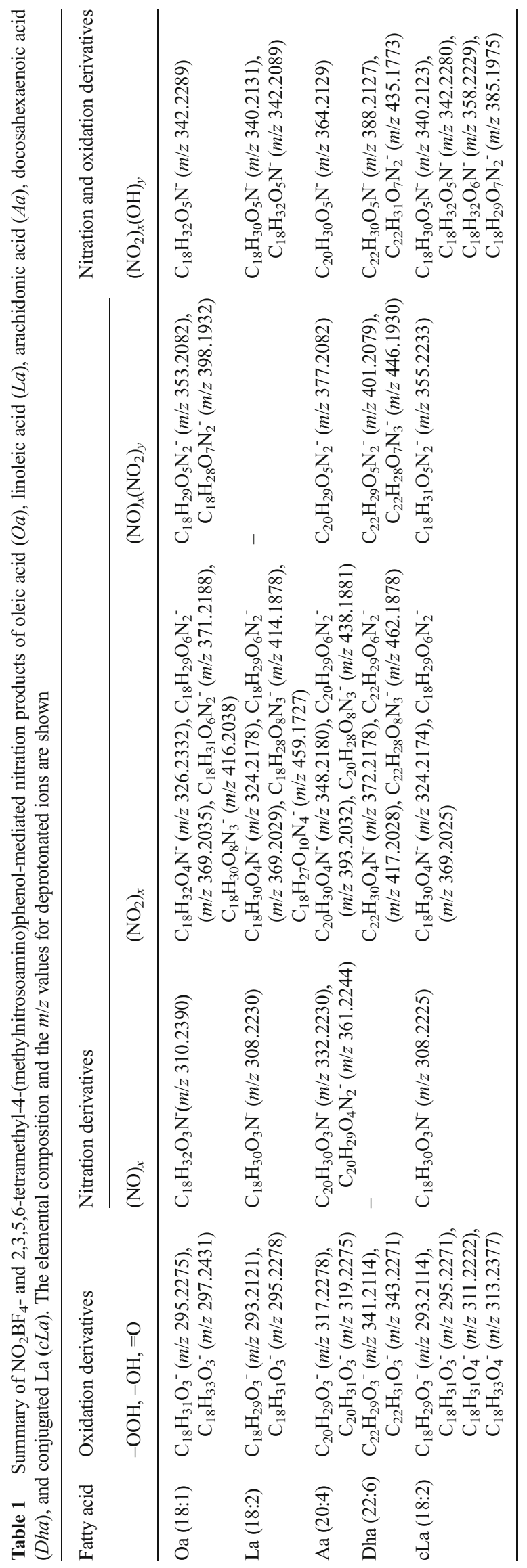


La was observed at $m / z 279.23$, indicating that $\mathrm{La}$ was not fully consumed within $1 \mathrm{~h}$ in the reaction with $\mathrm{NO}_{2}{ }^{+}$. Signals corresponding to $\mathrm{LaNO}_{2}(\mathrm{~m} / z$ 324.22), dinitro-La $\left[\mathrm{La}\left(\mathrm{NO}_{2}\right)_{2} ; m / z\right.$ 369.20], trinitro-La $\left[\mathrm{La}\left(\mathrm{NO}_{2}\right)_{3} ; \mathrm{m} / z\right.$ 414.19], and tetranitro- $\mathrm{La}\left[\mathrm{La}\left(\mathrm{NO}_{2}\right)_{4} ; \mathrm{m} / \mathrm{z} 459.17\right]$ suggested that the two double bonds allowed incorporation of up to four nitro groups. Unlike Oa nitration, La nitration yielded only one nitroso product, observed at $\mathrm{m} / \mathrm{z} 308.22$ (LaNO). Similarly to Oa nitration, hydroxynitro- $\mathrm{La}\left(\mathrm{LaNO}_{2} \mathrm{OH} ; \mathrm{m} / z\right.$ 340.21) and hydroxynitrooctadecenoic acid $\left(\mathrm{OaNO}_{2} \mathrm{OH} ; \mathrm{m} / z\right.$ 342.23) were also detected.

ESI Orbitrap mass spectra of Aa (Fig. 1c) and Dha (Fig. 1d) nitration mixtures displayed the deprotonated fatty acid ions as base peaks ( $m / z 303.23$ and $m / z 327.23$, respectively), and the relative signal intensities of all nitration products were below $10 \%$. This observation indicated significantly lower susceptibilities of $\mathrm{Aa}$ and Dha to $\mathrm{NO}_{2}{ }^{+}$-mediated nitration compared with $\mathrm{Oa}$ and $\mathrm{La}$. Both $\mathrm{Aa}$ and Dha were oxidized to keto derivatives $(\mathrm{m} / \mathrm{z} 317.23, \mathrm{AaO} ; \mathrm{m} / \mathrm{z} 341.21$, $\mathrm{DhaO})$ and hydroxy derivatives $(m / z$ 319.23, $\mathrm{AaOH} ; m / z$ 343.23, $\mathrm{DhaOH})$. Mass spectra of both $\mathrm{Aa}$ and Dha nitration mixtures revealed the presence of nitro derivatives $(\mathrm{m} / \mathrm{z}$ 348.22, $\mathrm{AaNO}_{2} ; \mathrm{m} / z$ 372.22, $\mathrm{DhaNO}_{2}$ ), dinitro derivatives $\left[m / z\right.$ 393.20, $\mathrm{Aa}\left(\mathrm{NO}_{2}\right)_{2} ; m / z 417.20$, $\left.\mathrm{Dha}\left(\mathrm{NO}_{2}\right)_{2}\right]$, and trinitro derivatives $\left[m / z 438.19, \mathrm{Aa}\left(\mathrm{NO}_{2}\right)_{3} ; m / z\right.$ 462.19, $\left.\mathrm{Dha}\left(\mathrm{NO}_{2}\right)_{3}\right]$. Additionally, nitroso-Aa (AaNO; $m / z$ 332.22), dinitro-Aa $\left[\mathrm{Aa}(\mathrm{NO})_{2} ; m / z\right.$ 361.22], and nitrosonitro-Aa $\left(\mathrm{AaNO}_{2} \mathrm{NO}\right.$, $m / z 377.21)$ as well as nitrosonitro-Dha $\left(\mathrm{DhaNO}_{2} \mathrm{NO}\right.$, $m / z$ 401.21) and nitrosodinitro-Dha $\left[\mathrm{Dha}\left(\mathrm{NO}_{2}\right)_{2} \mathrm{NO}, \mathrm{m} / \mathrm{z}\right.$ 446.19] were detected. Weak signals were observed for nitro-oxidized $\mathrm{Aa}$ and Dha-namely, hydroxynitro-Aa $\left(\mathrm{AaNO}_{2} \mathrm{OH} ; \mathrm{m} / z\right.$ 364.21), hydroxynitro-Dha $\left(\mathrm{DhaNO}_{2} \mathrm{OH}\right.$; $\mathrm{m} / \mathrm{z} 388.21$ ), and hydroxydinitrodocosapentaenoic acid [Dpa( $\left(\mathrm{NO}_{2}\right)_{2} \mathrm{OH} ; m / z$ 435.18,].

Electrophilic fatty acid nitration by nitronium ions under low oxygen tension resulted in a high diversity of modified Oa, La, Aa, and Dha. ESI Orbitrap MS spectra acquired after a reaction time of $1 \mathrm{~h}$ (Fig. 1) revealed different susceptibilities. To the best of our knowledge, this is the first report on in vitro nitration of Dha. Besides single-nitro fatty acids, the formation of polynitro fatty acids was observed for each fatty acid. Regardless of a higher unsaturation degree of $\mathrm{Aa}$ (C20:4) and Dha (C22:6), these two fatty acids were detected with up to three nitro groups introduced along the alkyl chain, whereas for La with two double bonds even a tetranitro derivative was present. Our data indicate lower susceptibilities of Aa and Dha toward nitration in general and especially the formation of multiple nitration derivatives compared with $\mathrm{Oa}$ and $\mathrm{La}$. The relative signal intensities of the modified species decreased with increasing fatty acid chain lengths and the numbers of double bonds in PUFA. Additionally, the low oxygen tension conditions applied here minimized formation of oxidized fatty acids and nitrohydroxy fatty acids.
$M S / M S$ of $N_{2}-F A$

The CID and HCD fragmentation behavior of nitrated PUFA was studied using HR-MS/MS in order to evaluate the diversity of positional isomers on the basis of previously published mechanisms [37] (see Figs. S1-S4, Scheme S1). Neutral loss of nitrous acid $\left(\mathrm{HNO}_{2} ;-47 \mathrm{u}\right)$ produced under the CID conditions was observed in all tandem mass spectra of $\mathrm{NO}_{2}-\mathrm{FA}$, and served as a reporter ion for the presence of the nitro group. Although successful nitration of $\mathrm{Oa}, \mathrm{La}$, and $\mathrm{Aa}$ and analysis of the corresponding MS/MS spectra was previously reported, to the best of our knowledge, this is the first report of Dha nitration. Since in the MS/MS spectrum of deprotonated DhaNO ${ }_{2}$ the parent ion dominates the spectrum, and fragmentation of the alkyl chain was poor, we used the lithiated ion of $\mathrm{DhaNO}_{2}$ for the fragmentation. We relied on the fragmentation mechanism previously reported by Bonacci et al. [37] to predict a series of fragment ions of each nitro-Dha $\left(\mathrm{DhaNO}_{2}\right)$ isomer, and compared them with the recorded Fourier transform CID-MS/MS spectrum (Fig. 2). It was possible to match 12 product ions, including structure-specific ions for seven nitro-Dha isomers, including $11-\mathrm{NO}_{2}$ - Dha $(\mathrm{m} / z \mathrm{161.08)}), 13-$ $\mathrm{NO}_{2}$-Dha $\left(m / z\right.$ 175.09), 14- $\mathrm{NO}_{2}$-Dha $\left(m / z\right.$ 201.11), 16- $\mathrm{NO}_{2}-$ Dha $\left(m / z\right.$ 215.12), 17- $-\mathrm{NO}_{2}$-Dha $\left(m / z\right.$ 241.14), 19- $\mathrm{NO}_{2}-\mathrm{Dha}$ $(\mathrm{m} / \mathrm{z} 255.16)$, and $20-\mathrm{NO}_{2}$-Dha $(\mathrm{m} / \mathrm{z} 281.17)$. Fragment ions containing a nitrogen atom were not detected.

Similarly, the tandem mass spectrum of $\left[\mathrm{AaNO}_{2}+\mathrm{Li}^{+}\right]^{+}$ recorded using HCD fragmentation and detection in the Orbitrap mass analyzer (Fig. S2) confirmed the presence of five $\mathrm{AaNO}_{2}$ vinyl isomers - namely, 9- $\mathrm{NO}_{2}-\mathrm{Aa}, 11-\mathrm{NO}_{2}-\mathrm{Aa}$, $12-\mathrm{NO}_{2}-\mathrm{Aa}, 14-\mathrm{NO}_{2}-\mathrm{Aa}$, and $15-\mathrm{NO}_{2}-\mathrm{Aa}$ (Fig. S2, Scheme $\mathrm{S} 1$ ). We did not observe fragment ions specific for 5- $\mathrm{NO}_{2}-\mathrm{Aa}, 6-\mathrm{NO}_{2}-\mathrm{Aa}$, and $8-\mathrm{NO}_{2}-\mathrm{Aa}$ or $4-\mathrm{NO}_{2}-\mathrm{Dha}$, 5- $\mathrm{NO}_{2}-$ Dha, 7- $\mathrm{NO}_{2}-\mathrm{Dha}, 8-\mathrm{NO}_{2}$-Dha, and $10-\mathrm{NO}_{2}$-Dha. However, it cannot be ruled out that isomers of nitro fatty acids with the $\mathrm{NO}_{2}$ group localized at the first three vinyl carbons are formed, but with lower yields compared with the other isomers, and thus the corresponding ions will result in signal intensities below the limit of detection of the Orbitrap mass analyzer. Furthermore, the fragmentation pattern might be different for the isomers with the $\mathrm{NO}_{2}$ group near the carboxy group. Nevertheless, Trostchansky et al. [31] performed in vitro nitration of Aa by sodium nitrite under acidic conditions, and also observed only four major isomers of nAaNO ${ }_{2}$-namely, 9- $\mathrm{NO}_{2}-\mathrm{Aa}, 12-\mathrm{NO}_{2}-\mathrm{Aa}, 14-\mathrm{NO}_{2}-\mathrm{Aa}$, and $15-\mathrm{NO}_{2}$-Aa.

Further, in vitro nitrated PUFA mixtures were used to optimize MRM parameters, including precursor to product ion transitions in a series of direct infusion experiments (Table S1). This in vitro approach allowed us to specify 91 different transition pairs for the simultaneous relative quantification of 42 nitrated, oxidized, and nitro-oxidized PUFA, which was further validated as part of the nitration kinetics study. 

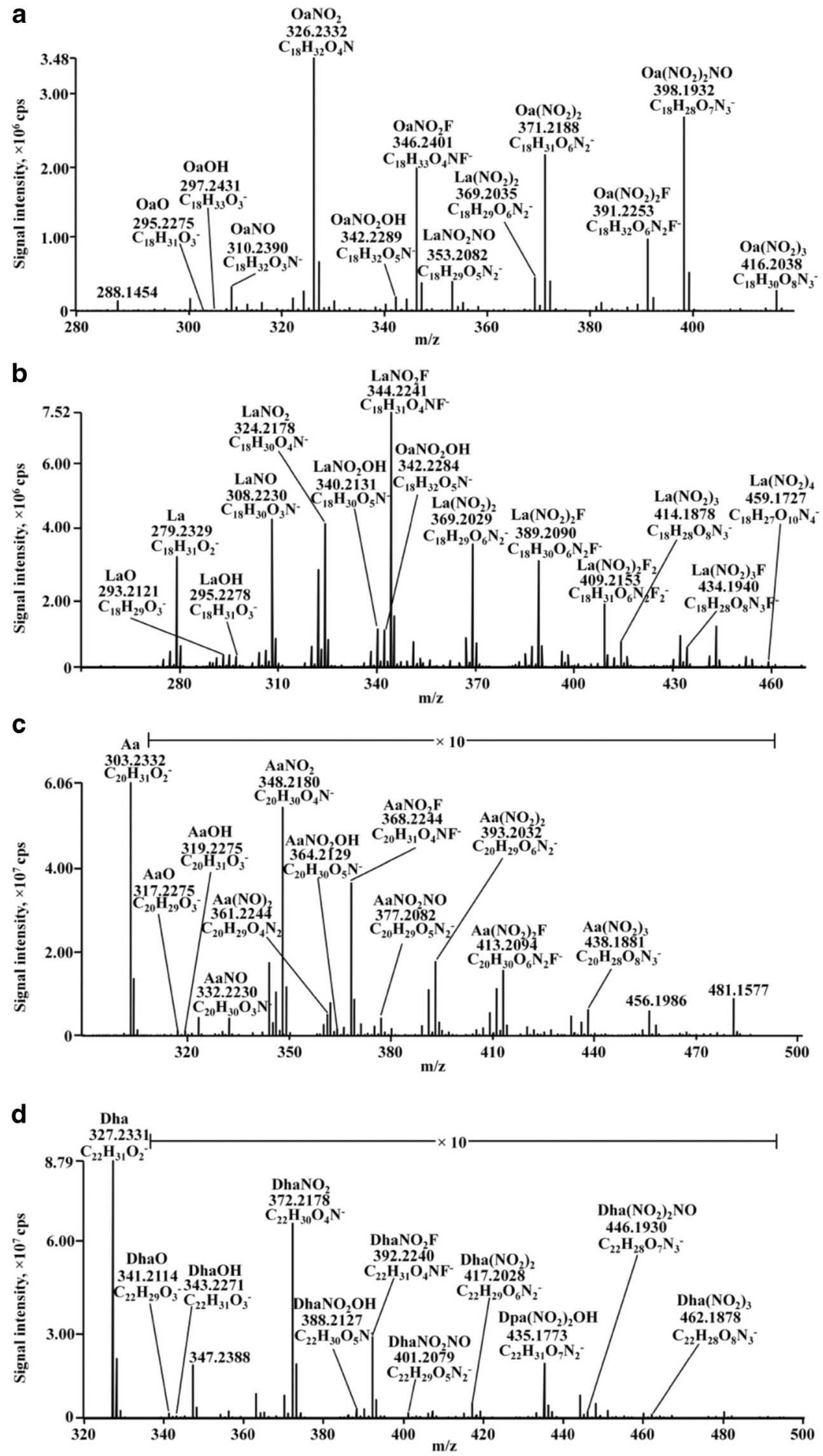
Fig. 1 Electrospray ionization (ESI) Orbitrap mass spectrometry spectra recorded after $1 \mathrm{~h}$ of oleic acid (Oa; a), linoleic acid (La; b), arachidonic acid $(\mathrm{Aa} ; \mathbf{c})$ and docosahexaenoic acid (Dha; d) nitration with nitronium tetrafluoroborate

Kinetics of $\mathrm{NO}_{2}{ }^{+}$-mediated nitration of $\mathrm{Oa}$, La, Aa, and Dha

The kinetics of PUFA nitration by $\mathrm{NO}_{2}{ }^{+}$was monitored by MRM-based ESI-MS/MS. Altogether, we were able to monitor eight, nine, eight, and five products of $\mathrm{Oa}, \mathrm{La}, \mathrm{Aa}$, and
Dha nitration and oxidation, respectively (see Figs S5-S8). Except for $\mathrm{OaO}$, all monitored oxidized fatty acids (i.e., $\mathrm{LaO}, \mathrm{LaOH}, \mathrm{AaO}, \mathrm{AaOH}$, and DhaO) were formed immediately, and then their quantities decreased constantly, most likely due to further nitration by $\mathrm{NO}_{2}{ }^{+}$ions. Among the singly nitrated derivatives, $\mathrm{OaNO}_{2}$ was formed the fastest, with a mild increase over the following $60 \mathrm{~min}$. The quantities of $\mathrm{LaNO}_{2}$ and $\mathrm{AaNO}_{2}$ increased several fold until the maxima were reached after 30 and $15 \mathrm{~min}$, respectively, whereas the quantity of $\mathrm{DhaNO}_{2}$ increased over the whole reaction period.
Fig. 2 ESI Fourier transform collision-induced dissociation spectrum of nitro-Dha (lithiated precursor at $\mathrm{m} / \mathrm{z} 380.24$; upper panel) and schematic annotation for structure-specific product ions (1-11; lower panel)
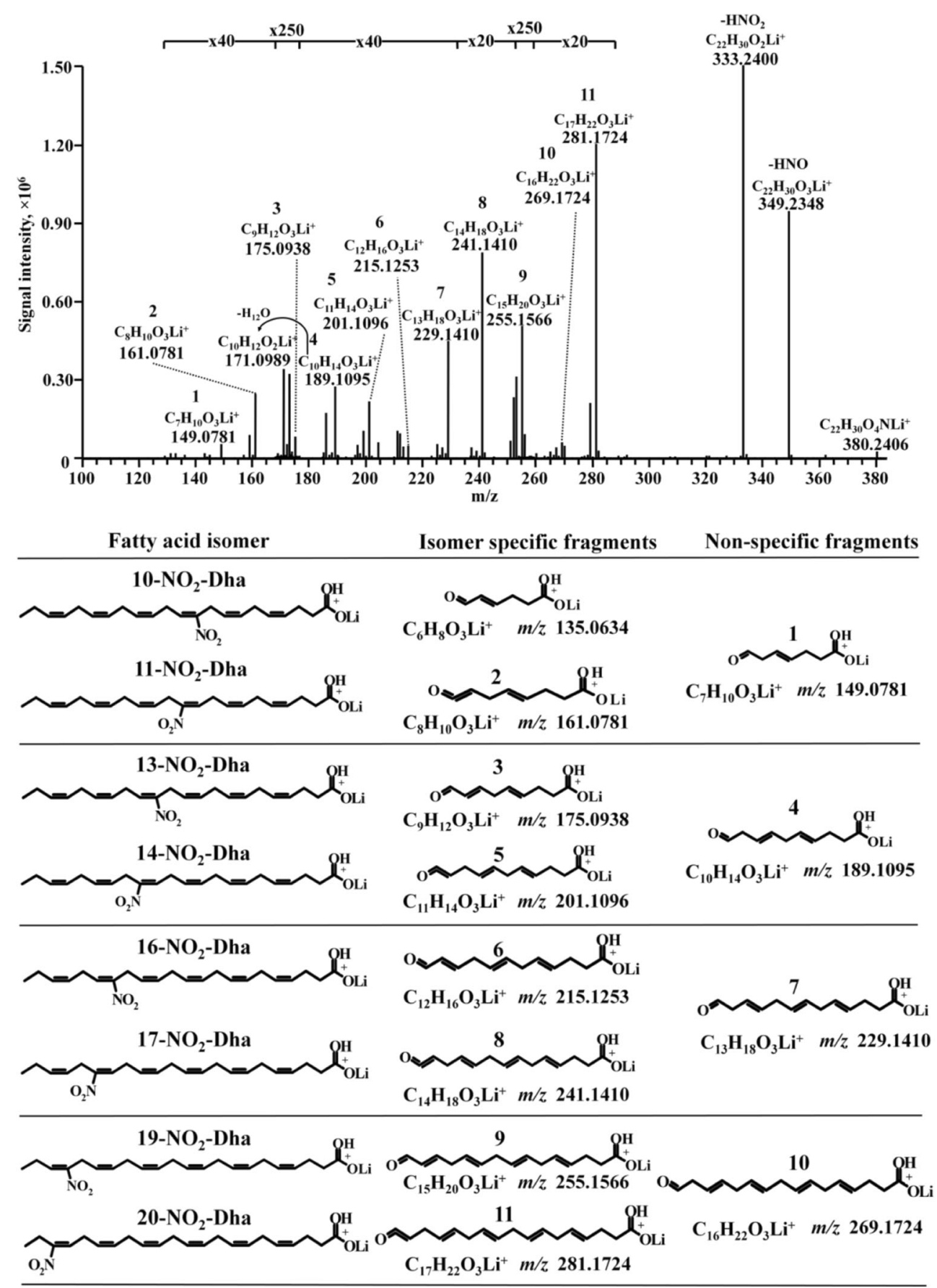
Nitro fatty acids via further reactions with $\mathrm{NO}_{2}{ }^{+}$ions yield multiply nitrated fatty acids, which was observed for Oa, La, $\mathrm{Aa}$, and Dha. The nitration kinetics revealed that Aa and Dha with longer alkyl chains and more double bonds than $\mathrm{Oa}$ and $\mathrm{La}$ are less reactive toward nitronium ions. Maximal levels of $\mathrm{Oa}\left(\mathrm{NO}_{2}\right)_{2}$ and $\mathrm{Aa}\left(\mathrm{NO}_{2}\right)_{2}$ were reached after $60 \mathrm{~min}$, and the level of $\mathrm{La}\left(\mathrm{NO}_{2}\right)_{2}$ gradually increased over the reaction time course. The kinetics of Dha $\left(\mathrm{NO}_{2}\right)_{2}$ formation suggests that the product is formed at the reaction onset and quantity decreases in the first $60 \mathrm{~min}$. Finally, nitro-oxidized products of $\mathrm{Oa}$ and $\mathrm{La}\left(\mathrm{OaNO}_{2} \mathrm{OH}\right.$ and $\left.\mathrm{LaNO}_{2} \mathrm{OH}\right)$ showed an overall increase in the detected levels, whereas maximal levels of nitro-oxidized $\mathrm{Aa}$ and Dha $\left(\mathrm{AaNO}_{2} \mathrm{OH}, \mathrm{DhaNO}_{2} \mathrm{OH}\right)$ were observed at the reaction onset, suggesting that the formed $\mathrm{AaOH}$ and $\mathrm{DhaOH}$ are readily consumed in further reactions with $\mathrm{NO}_{2}{ }^{+}$ions.

\section{HR-MS detection of cLa nitration by P-NAP}

Use of the UV-inducible peroxynitrite donor P-NAP was recently introduced. It releases $\mathrm{NO}$, which reacts under aerobic conditions with $\mathrm{O}_{2}{ }^{--}$, producing a peroxynitrite anion $\left(\mathrm{ONOO}^{-}\right)$[33], which forms $\cdot \mathrm{NO}_{2}$, an RNS capable of nitrating fatty acids in vivo or lipid radicals yielding nitro fatty acids and hydroxynitro fatty acids. Thus, we used P-NAP as an $\mathrm{ONOO}^{-}$donor in aqueous solutions to investigate fatty acid nitration for biologically more relevant conditions.

As a recent study identified cLa as a better substrate for nitration than bisallylic La in vitro and in vivo [12], we selected cLa as the substrate for P-NAP nitration (Fig. 3a). UV irradiation will induce peroxynitrite generation from P-NAP and additionally produce ROS, thus providing both ROS and RNS simultaneously, mimicking closely pathophysiological conditions. Signals corresponding to nitro-cLa $\left(\mathrm{cLaNO}_{2} ; \mathrm{m} / \mathrm{z}\right.$ $324.22)$ and dinitro-cLa $\left[\mathrm{cLa}\left(\mathrm{NO}_{2}\right)_{2} ; m / z\right.$ 369.20] confirmed that P-NAP triggers free-radical-mediated nitration of cLa. Although $\mathrm{La}\left(\mathrm{NO}_{2}\right)_{2}$ is present with considerably lower relative signal intensities than after nitration of $\mathrm{La}$ by $\mathrm{NO}_{2} \mathrm{BF}_{4}$, the formation of $\mathrm{La}\left(\mathrm{NO}_{2}\right)_{2}$ by P-NAP suggests that multiple nitration derivatives can be formed via reaction with $\cdot \mathrm{NO}_{2}$. Free-radical-mediated nitration of cLa under high oxygen tension yielded additionally four oxidation products - namely, keto-cLa (cLaO; $m / z$ 293.21), hydroxy-cLa (cLaOH; $m / z$ 295.23), hydroperoxy-cLa ( $\mathrm{cLaOOH} ; \mathrm{m} / z$ 311.22), and hydroperoxyoctadecenoic acid $(\mathrm{OaOOH} ; \mathrm{m} / \mathrm{z} 313.23)$. Among all the oxidation products, these showed the highest relative intensities. Moreover, several derivatives of cLa resulted from simultaneous oxidation and nitration, including hydroxynitro-cLa $\left(\mathrm{cLaNO}_{2} \mathrm{OH} ; \mathrm{m} / z\right.$ 340.21), hydroxynitrooctadecenoic acid $\left(\mathrm{OaNO}_{2} \mathrm{OH} ; \mathrm{m} / z\right.$ 342.23), hydroperoxynitrooctadecaenoic acid $\left(\mathrm{OaNO}_{2} \mathrm{OOH} ; \mathrm{m} / \mathrm{z}\right.$ $358.22)$, and hydroxydinitro-cLa $\left[\mathrm{cLa}\left(\mathrm{NO}_{2}\right)_{2} \mathrm{OH} ; \mathrm{m} / z\right.$ 385.20]. Additionally, nitroso derivatives were present after free-radical-mediated cLa nitration-namely, nitroso-cLa
(cLaNO; $m / z$ 308.22) and nitronitrosooctadecenoic acid $\left(\mathrm{OaNO}_{2} \mathrm{NO} ; \mathrm{m} / \mathrm{z} 355.22\right)$-indicating that nitroso derivatives are most likely formed from nitro fatty acids, independently of the fatty acid nitration mechanism. cLa nitration mixtures were used for further optimization of the MRM method (Table S1).

The kinetics of nitration of cLa by P-NAP was monitored using specific MRM transitions of four oxidation, four nitration, and four nitro-oxidation products (Fig. 3b). UV irradiation of P-NAP readily releases $\mathrm{ONOO}^{-}$with tenfold increased levels within $15 \mathrm{~min}$ [33]. Thus, cLa nitration was monitored for shorter time intervals within the first $15 \min (0,3,6,9$, and $15 \mathrm{~min}$ ) and then for 30,60 , and $120 \mathrm{~min}$ of the nitration reaction. Conditions of higher oxygen tension favored fatty acid oxidation compared with the hydrophobic conditions of $\mathrm{NO}_{2} \mathrm{BF}_{4}$ nitration, yielding more oxidized $\mathrm{cLaNO}_{2}$ derivatives. The concentrations of $\mathrm{cLaOOH}, \mathrm{cLaOH}, \mathrm{cLaO}$, and $\mathrm{OaOOH}$ increased over the whole reaction period. Two main mechanisms have been proposed for free-radical-induced nitration of fatty acids [38]. One suggests the abstraction of a bisallylic hydrogen followed by the reaction with $\bullet \mathrm{NO}_{2}$, producing vinylnitro isomers. The second mechanism predicts a homolytic attack of $\cdot \mathrm{NO}_{2}$ at the $\mathrm{C}=\mathrm{C}$-bond, yielding a $\beta$ nitroalkyl radical that can lose a hydrogen atom and form nitroalkenes. Owing to the absence of bisallylic hydrogens in $\mathrm{cLaNO}_{2}$, this product is most likely formed by the second mechanism. The kinetics of $\mathrm{cLaNO}_{2}$ formation showed that maximal amounts of $\mathrm{cLaNO}_{2}$ were reached after 6 min and then the amounts decreased rapidly until $15 \mathrm{~min}$, reaching stable levels after $60 \mathrm{~min}$. Indeed, this fast decrease between 6 and 15 min can be explained by the homolytic attack of a second $\cdot \mathrm{NO}_{2}$ responsible for the increased levels of $\mathrm{cLa}\left(\mathrm{NO}_{2}\right)_{2}$ (maximum at $15 \mathrm{~min}$ ). Similarly, $\mathrm{CLaNO}_{2}$ can also react with $\cdot \mathrm{OH}$ to form $\mathrm{cLaNO}_{2} \mathrm{OH}$ and $\mathrm{cLa}\left(\mathrm{NO}_{2}\right)_{2} \mathrm{OH}$. Additionally, nitroalkyl radicals formed by the homolytic attack of a second $\cdot \mathrm{NO}_{2}$ can produce a nitronitrite derivative, hydrolysis of which can further result in hydroxynitroalkenes, such as $\mathrm{OaNO}_{2} \mathrm{OH}$ and $\mathrm{OaNO}_{2} \mathrm{OOH}$. The formation rates of $\mathrm{cLaNO}_{2} \mathrm{OH}$ and $\mathrm{OaNO}_{2} \mathrm{OH}$ are clearly different. Whereas the $\mathrm{OaNO}_{2} \mathrm{OH}$ levels increase fast within the first $6 \mathrm{~min}$, reaching relatively stable values, the $\mathrm{cLaNO}_{2} \mathrm{OH}$ and $\mathrm{cLa}\left(\mathrm{NO}_{2}\right)_{2} \mathrm{OH}$ levels increase gradually over the full reaction period. The possibility that oxidized cLa is nitrated was also considered. The half-lives of $\bullet \mathrm{OH}$ and $\bullet \mathrm{OOH}\left(10^{-9} \mathrm{~s}\right)[39]$ are significantly shorter than the half-life of $\cdot \mathrm{NO}_{2}\left(10^{-5}-10^{-4} \mathrm{~s}\right)[40]$. Additionally, the reaction rates of an olefinic double bond with $\cdot \mathrm{OH}$ and $\bullet \mathrm{OOH}\left(10^{8} \mathrm{M}^{-1} \mathrm{~s}^{-1}\right)$ [39] are much faster than with

Fig. 3 (a) ESI Orbitrap mass spectrum of conjugated La (cLa) incubated with the peroxynitrite donor 2,3,5,6-tetramethyl-4(methylnitrosoamino)phenol for $15 \mathrm{~min}$. (b) Kinetics of cLa nitration monitored by multipole reaction monitoring (MRM) optimized for 12 cLa derivatives for $2 \mathrm{~h}$ 


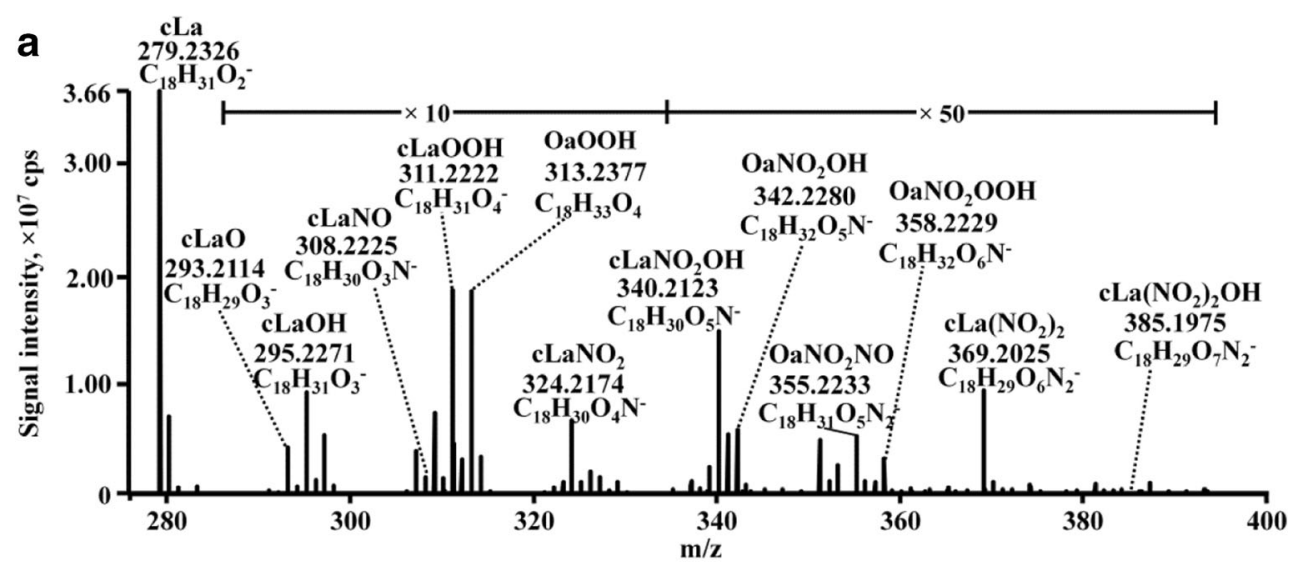

b

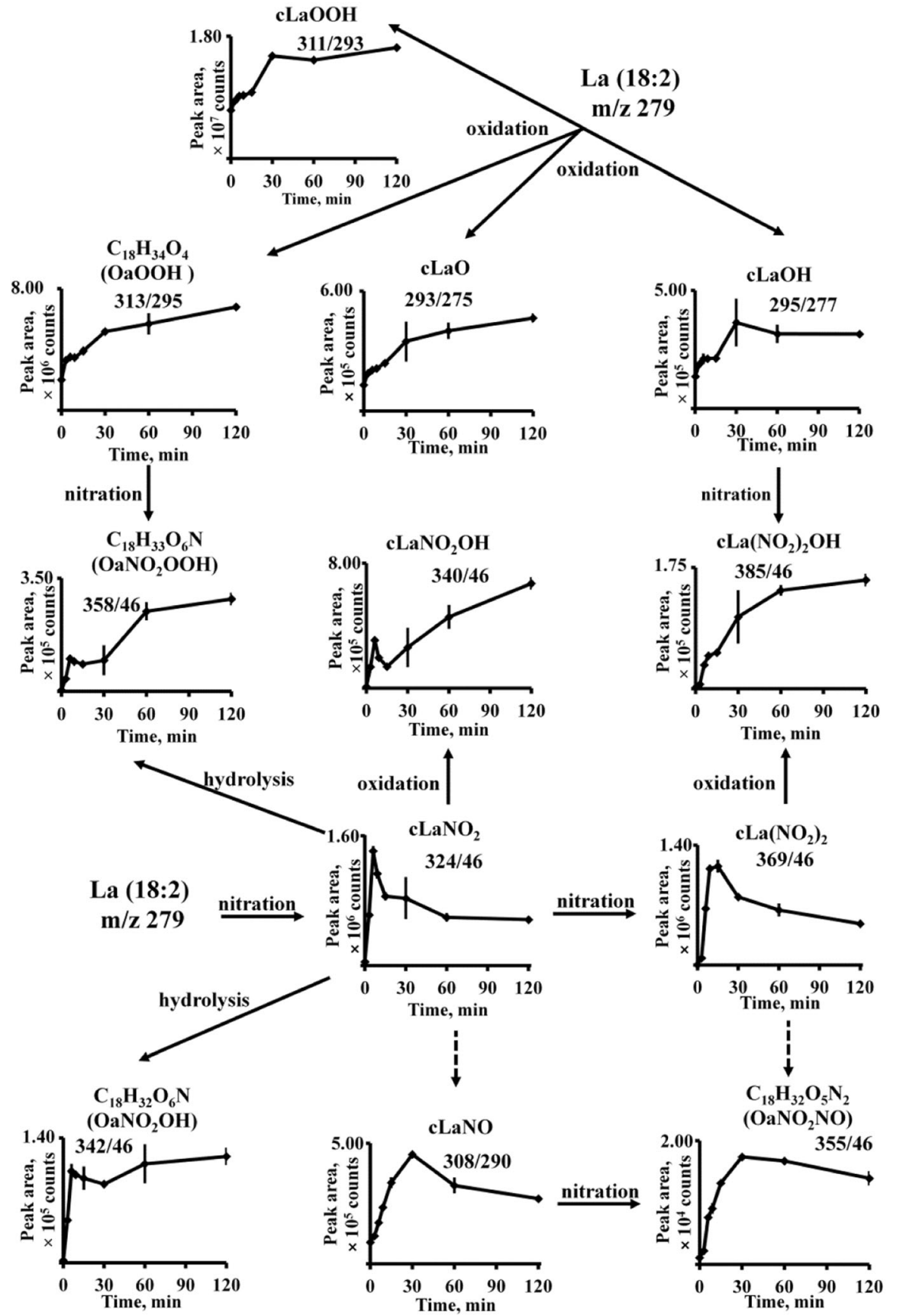


$\cdot \mathrm{NO}_{2}\left(10^{6}-10^{7} \mathrm{M}^{-1} \mathrm{~s}^{-1}\right)$ [40]. Thus, it appears very likely that oxidation occurs first and nitration follows. Both processes can produce $\mathrm{cLaNO}_{2} \mathrm{OH}$ and $\mathrm{cLa}\left(\mathrm{NO}_{2}\right)_{2}$, although their individual contributions remain to be defined. Hydroperoxy and hydroxy derivatives of $\mathrm{NO}_{2}$-FA accumulate over time, and thus might provide a better "chemical fingerprint" of nitrosative stress than $\mathrm{NO}_{2}$-FA itself. Finally, we observed formation of nitroso derivatives, including cLaNO and $\mathrm{OaNO}_{2} \mathrm{NO}$, reaching the highest concentrations after $30 \mathrm{~min}$ before decreasing afterward.

The kinetics of electrophilic $\left(\mathrm{NO}_{2}{ }^{+}\right)$and free radical $\left(\cdot \mathrm{NO}_{2}\right)$ driven fatty acid nitrations are determined by the reaction conditions. Nevertheless, both electrophilic and free-radicaldriven nitration of fatty acids successfully produced a wide array of products. Fatty acids nitrated with $\mathrm{NO}_{2}{ }^{+}$under low oxygen tension yielded low levels of oxidized fatty acids, whereas high oxygen tension continuously produced oxidized fatty acids. Similar kinetics were observed for singly nitrated fatty acids for both nitration reactions, indicating that regardless of the nature of the RNS and the chemical environment, $\mathrm{NO}_{2}$-FA do not represent the final products, but are prone to further nitration and oxidation reactions.

\section{$\mathrm{NO}_{2}$-FA in the cardiomyocyte nitrosative stress model}

Following successful application of the new MRM method for simultaneous detection of nitrated and nitro-oxidized PUFA in kinetics experiments, we used this approach for relative quantification of modified PUFA in a cellular model of nitrosative stress using LC-MS coupling. Retention-time mapping was performed using each in vitro fatty acid nitration mixture separately and in combinations. Oxidation products with the same elemental composition (same $\mathrm{m} / \mathrm{z}$ values) derived from different precursors, such as $\mathrm{OaO}$ and $\mathrm{LaOH}(m / z 295.2)$ have different functional groups (keto and hydroxy), and reversedphase high-performance LC separation of these fatty acids results in different elution times of isobaric analytes, which allowed us to perform structure-specific retention-time mapping. Rat primary cardiomyocytes were treated with the peroxynitrite donor SIN-1 $(10 \mu \mathrm{M})$ for 15,30 , and $70 \mathrm{~min}$, and the levels of modified PUFA in lipid extracts were compared with those in untreated cells. The most sensitive MRM transitions optimized for each modified fatty acid were used (Table S1). Under the CID conditions, nitro fatty acids exhibit strong neutral loss of nitrous acid. Thus, for each nitration and oxidation/nitration derivative, the product ion of deprotonated nitrous acid $\left(\mathrm{NO}_{2}^{-} ; \mathrm{m} / \mathrm{z} 46\right)$, and the product ions of single or multiple neutral losses of $\mathrm{HNO}_{2}$ were monitored. These transitions were, without exception, more sensitive than any isomer-specific ones. Moreover, a fast reversed-phase LC gradient was designed, providing higher sensitivities owing to co- elution of different isomers. The specificity of the LC-MS method was ensured by compound-specific retention-time mapping using mixtures of in vitro nitrated fatty acids. Thus, identification of the free and modified fatty acids in the cell model was based on the retention time and quadrupole 1/quadrupole 3 specific transitions for each compound.

The stability of endogenous $\mathrm{NO}_{2}$-FA is largely unknown. Owing to the absence of authentic isotopically labeled nitro fatty acid standards, we were unable to estimate compound stability or determine the limits of detection. Although artificial oxidation cannot be excluded, it is generally believed that the MTBE-methanol hydrophobic environment used here for lipid extraction in combination with low temperatures $\left(4^{\circ} \mathrm{C}\right)$ minimizes artificial oxidation of lipids. Nitro fatty acids were shown to be stabile under hydrophobic conditions, and organic extractions offer the highest recoveries of nitro fatty acids from samples [38]. Work by Baker et al. [15] indicates the level of $\mathrm{OaNO}_{2}$ decays by $10 \%$ when it is stored in methanol for 1 month, while $40 \%$ loss was observed in phosphate buffer after $2 \mathrm{~h}$. $\mathrm{LaNO}_{2}$ showed higher instability, probably owing to the higher unsaturation degree. This indicates that $\mathrm{AaNO}_{2}$ and $\mathrm{DhaNO}_{2}$ might decay even faster than $\mathrm{OaNO}_{2}$ and $\mathrm{LaNO}_{2}$.

Apart from $\mathrm{Oa}, \mathrm{La}, \mathrm{Aa}$ and Dha, we detected and relatively quantified four oxidized fatty acids $(\mathrm{OaOH}$, $\mathrm{LaOH}, \mathrm{LaOOH}, \mathrm{AaOH})$, four $\mathrm{NO}_{2}-\mathrm{FA}\left[\mathrm{Oa}\left(\mathrm{NO}_{2}\right)_{2}, \mathrm{AaNO}_{2}\right.$, DhaNO $\left.\mathrm{O}_{2}, \mathrm{Dha}\left(\mathrm{NO}_{2}\right)_{2}\right]$ and two oxidized/nitrated fatty acids [DhaNO $\left.{ }_{2} \mathrm{OH}, \mathrm{Dpa}\left(\mathrm{NO}_{2}\right)_{2} \mathrm{OH}\right]$ (Table 2, Figs. 4, S9). Induction of stress in the cardiomyocytes resulted in an increase in free fatty acid concentrations. After 15 min from stress onset, the levels of free La and Dha mildly increased (161\% and $155 \%$ relative to the control for La and Dha, respectively; see Fig. S9), whereas approximately doubled levels of Oa and Aa (193\% for Oa; $183 \%$ for Aa) were detected. An increase in the concentration of free fatty acids can be connected to elevated activity of phospholipase $A_{2}$ $\left(\mathrm{PLA}_{2}\right)$. Several studies showed that as a response to cell membrane lipid peroxidation, catalytic activity of $\mathrm{PLA}_{2}$ is enhanced, leading to increases in the levels of free fatty acids and lysophospholipids [41, 42]. An increase in the levels of oxidized fatty acids in the first $30 \mathrm{~min}$ from stress onset was observed for $\mathrm{La}(168 \%$ and $150 \%$ for $\mathrm{LaOH}$ and $\mathrm{LaOOH}$, respectively) and $\mathrm{Aa}(169 \%$ for $\mathrm{AaOH})$, whereas the highest increase was detected for $\mathrm{OaOH}(234 \%)$. The increases in the levels of $\mathrm{OaOH}, \mathrm{LaOH}, \mathrm{LaOOH}$, and $\mathrm{AaOH}$ in the first 30 min can be accounted for by direct PUFA oxidation as well as increased activities of $\mathrm{PLA}_{2}$ that could lead to the hydrolysis of hydroxylated and peroxidized fatty acids from phospholipids.

The relatively fast $\mathrm{LC}$ gradient resulted in co-elution of the single-nitro fatty acid derivatives, whereas multiply nitrated fatty acids and nitro-oxidized fatty acids appeared as multiple signals in the in vitro nitration mixtures. In the SIN-1-treated 
Table 2 Relative quantification of unmodified, oxidized, nitrated, and nitro-oxidized fatty acids detected after 15, 30, and 70 min of 3morpholinosydnonimine treatment in rat primary cardiomyocytes shown as a percentage relative to the control (control=100 \%)

\begin{tabular}{|c|c|c|c|c|c|c|c|}
\hline \multirow[t]{2}{*}{ Class } & \multirow[t]{2}{*}{ Analyte } & \multicolumn{2}{|l|}{$15 \mathrm{~min}$} & \multicolumn{2}{|l|}{$30 \mathrm{~min}$} & \multicolumn{2}{|l|}{$70 \mathrm{~min}$} \\
\hline & & $\begin{array}{l}\text { Percentage relative } \\
\text { to control } \pm \mathrm{SD}\end{array}$ & $p$ & $\begin{array}{l}\text { Percentage relative } \\
\text { to control } \pm \mathrm{SD}\end{array}$ & $p$ & $\begin{array}{l}\text { Percentage relative } \\
\text { to control } \pm \mathrm{SD}\end{array}$ & $p$ \\
\hline \multirow[t]{4}{*}{ Fatty acid } & $\mathrm{Oa}$ & $193 \pm 16$ & 0.014 & $198 \pm 85$ & 0.184 & $276 \pm 60$ & 0.049 \\
\hline & $\mathrm{La}$ & $161 \pm 22$ & 0.012 & $184 \pm 18$ & 0.0007 & $208 \pm 33$ & 0.005 \\
\hline & $\mathrm{Aa}$ & $183 \pm 30$ & 0.012 & $171 \pm 22$ & 0.006 & $171 \pm 27$ & 0.015 \\
\hline & Dha & $155 \pm 17$ & 0.006 & $161 \pm 18$ & 0.005 & $174 \pm 20$ & 0.003 \\
\hline \multirow[t]{4}{*}{ Oxidized fatty acid } & $\mathrm{OaOH}$ & $200 \pm 46$ & 0.047 & $234 \pm 61$ & 0.046 & $226 \pm 35$ & 0.011 \\
\hline & $\mathrm{LaOH}$ & $147 \pm 15$ & 0.009 & $168 \pm 31$ & 0.033 & $1,470 \pm 53$ & 0.205 \\
\hline & $\mathrm{LaOOH}$ & $117 \pm 3$ & 0.011 & $150 \pm 14$ & 0.036 & $164 \pm 64$ & 0.221 \\
\hline & $\mathrm{AaOH}$ & $163 \pm 12$ & 0.0005 & $169 \pm 12$ & 0.0002 & $157 \pm 21$ & 0.014 \\
\hline \multirow[t]{4}{*}{ Nitrated fatty acid } & $\mathrm{Oa}\left(\mathrm{NO}_{2}\right)_{2}$ & $173 \pm 41$ & 0.075 & $199 \pm 23$ & 0.006 & $228 \pm 78$ & 0.095 \\
\hline & $\mathrm{AaNO}_{2}$ & $141 \pm 43$ & 0.218 & $148 \pm 6$ & 0.007 & $115 \pm 28$ & 0.323 \\
\hline & $\mathrm{DhaNO}_{2}$ & $174 \pm 45$ & 0.121 & $230 \pm 32$ & 0.028 & $190 \pm 55$ & 0.122 \\
\hline & $\mathrm{Dha}\left(\mathrm{NO}_{2}\right)_{2}$ & $332 \pm 5$ & 0.0002 & $371 \pm 40$ & 0.011 & $226 \pm 22$ & 0.014 \\
\hline \multirow[t]{2}{*}{ Nitro-oxidized fatty acid } & $\mathrm{DhaNO}_{2} \mathrm{OH}$ & $131 \pm 24$ & 0.118 & $134 \pm 16$ & 0.030 & $131 \pm 26$ & 0.133 \\
\hline & $\mathrm{Dpa}\left(\mathrm{NO}_{2}\right)_{2} \mathrm{OH}$ & $345 \pm 33$ & 0.009 & $210 \pm 28$ & 0.031 & $369 \pm 54$ & 0.019 \\
\hline
\end{tabular}

$S D$ standard deviation

cardiomyocytes, the $\mathrm{Oa}\left(\mathrm{NO}_{2}\right)_{2}$-specific transition resulted in multiple signals at $5.82,7.47,7.98,8.72$, and $9.49 \mathrm{~min}$ (Fig. 4a). Using the retention-time mapping based on the in vitro $\mathrm{NO}_{2}{ }^{+}$nitration of $\mathrm{Oa}$, we were able to assign the peaks at 7.47 and $7.98 \mathrm{~min}$ to two $\mathrm{Oa}\left(\mathrm{NO}_{2}\right)_{2}$ isomers. After SIN-1 treatment, the levels of $\mathrm{Oa}\left(\mathrm{NO}_{2}\right)_{2}$ increased twofold compared with the levels in the untreated cells, reaching the maximal levels after $30 \mathrm{~min}$ from stress onset (199\%; Fig. 4a) and remained relatively stable after $70 \mathrm{~min}$. $\mathrm{AaNO}_{2}$ (retention time 8.33 min; Fig. 4b) and $\mathrm{DhaNO}_{2}$ (retention time $8.53 \mathrm{~min}$; Fig. 4c) reached maximal values after $30 \mathrm{~min}(148 \%$ for $\mathrm{AaNO}_{2} ; 230 \%$ for $\mathrm{DhaNO}_{2}$ ) of peroxynitrite treatment, followed by a mild decrease in the amounts detected.

Four signals $(6.99,7.65,8.09$, and $8.56 \mathrm{~min})$ were detected for the Dha $\left(\mathrm{NO}_{2}\right)_{2}$-specific transition for in vitro nitrated Dha (Fig. 4e). In the cardiomyocytes treated with SIN-1 for $15 \mathrm{~min}$, two $\mathrm{Dha}\left(\mathrm{NO}_{2}\right)_{2}$ peaks with similar intensities were observed at 8.20 and $8.66 \mathrm{~min}$, and were assigned to two different Dha $\left(\mathrm{NO}_{2}\right)_{2}$ isomers. The levels of Dha $\left(\mathrm{NO}_{2}\right)_{2}$ were significantly increased in the cardiomyocytes under the stress conditions compared with untreated cells, reaching the maximum at 30 min (371 \%; Fig. 4e).

For in vitro nitrated Dha, multiple signals of $\mathrm{DhaNO}_{2} \mathrm{OH}$ (6.47, 7.23, and 8.09 min; Fig. 2d) and $\mathrm{Dpa}\left(\mathrm{NO}_{2}\right)_{2} \mathrm{OH}(6.22$, $6.86,7.54,8.17$, and $9.50 \mathrm{~min}$; Fig. 4f) were detected. However, in cardiomyocyte lipid extracts, only the single peak for each compound was present. Thus, $\mathrm{DhaNO}_{2} \mathrm{OH}$ was eluted at $7.30 \mathrm{~min}$ and $\mathrm{Dpa}\left(\mathrm{NO}_{2}\right)_{2} \mathrm{OH}$ was eluted at $8.05 \mathrm{~min}$. The concentration of $\mathrm{DhaNO}_{2} \mathrm{OH}$ in SIN-1-treated cells mildly increased within the first $15 \mathrm{~min}(131 \%$; Fig. 4d) and remained stable afterward. On the other hand, the levels of $\mathrm{Dpa}\left(\mathrm{NO}_{2}\right)_{2} \mathrm{OH}$ significantly increased (345\%; Fig. $\left.4 \mathrm{f}\right)$ at $15 \mathrm{~min}$, decreased at $30 \mathrm{~min}(210 \%)$, and again increased at $70 \min (369 \%)$.

Overall, treatment of primary cardiomyocytes with the peroxynitrite donor resulted in increased amounts of oxidized fatty acids (approximately $150 \%$ compared with the untreated cells). The singly nitrated fatty acids - namely, $\mathrm{AaNO}_{2}$ and $\mathrm{DhaNO}_{2}$ - were detected with maximal levels at $30 \mathrm{~min}$, followed by a mild concentration decrease at $70 \mathrm{~min}$. The relative increase in the level of $\mathrm{DhaNO}_{2}(250 \%)$ at $30 \mathrm{~min}$ of SIN-1 treatment was approximately three times higher than that of $\mathrm{AaNO}_{2}(148 \%)$. The levels of $\mathrm{Oa}\left(\mathrm{NO}_{2}\right)_{2}$ doubled after 30 min (199 \%) and remained relatively stable afterward. Thus SIN-1 treatment of cardiomyocytes had the highest impact on the Dha nitration, resulting not only in pure nitration, but also in increased levels of nitration/oxidation derivatives. The highest and the fastest concentration increase of $\mathrm{Dpa}\left(\mathrm{NO}_{2}\right)_{2} \mathrm{OH}(245 \%)$ and $\mathrm{Dha}\left(\mathrm{NO}_{2}\right)_{2}(232 \%)$ in SIN-1treated cells compared with the untreated cells was detected after $15 \mathrm{~min}$ of stress induction. These results indicate that multiply nitrated and nitro-oxidized derivatives of fatty acids, including Dha, are produced in cells even under basal conditions, and the levels are significantly elevated in the peroxynitrite stress model. To the best of our knowledge, this is the first report of the endogenous formation of $\mathrm{AaNO}_{2}$, and Dha nitration products such as $\mathrm{DhaNO}_{2}, \mathrm{Dha}\left(\mathrm{NO}_{2}\right)_{2}$, $\mathrm{DhaNO}_{2} \mathrm{OH}$, and $\mathrm{Dpa}\left(\mathrm{NO}_{2}\right)_{2} \mathrm{OH}$. 

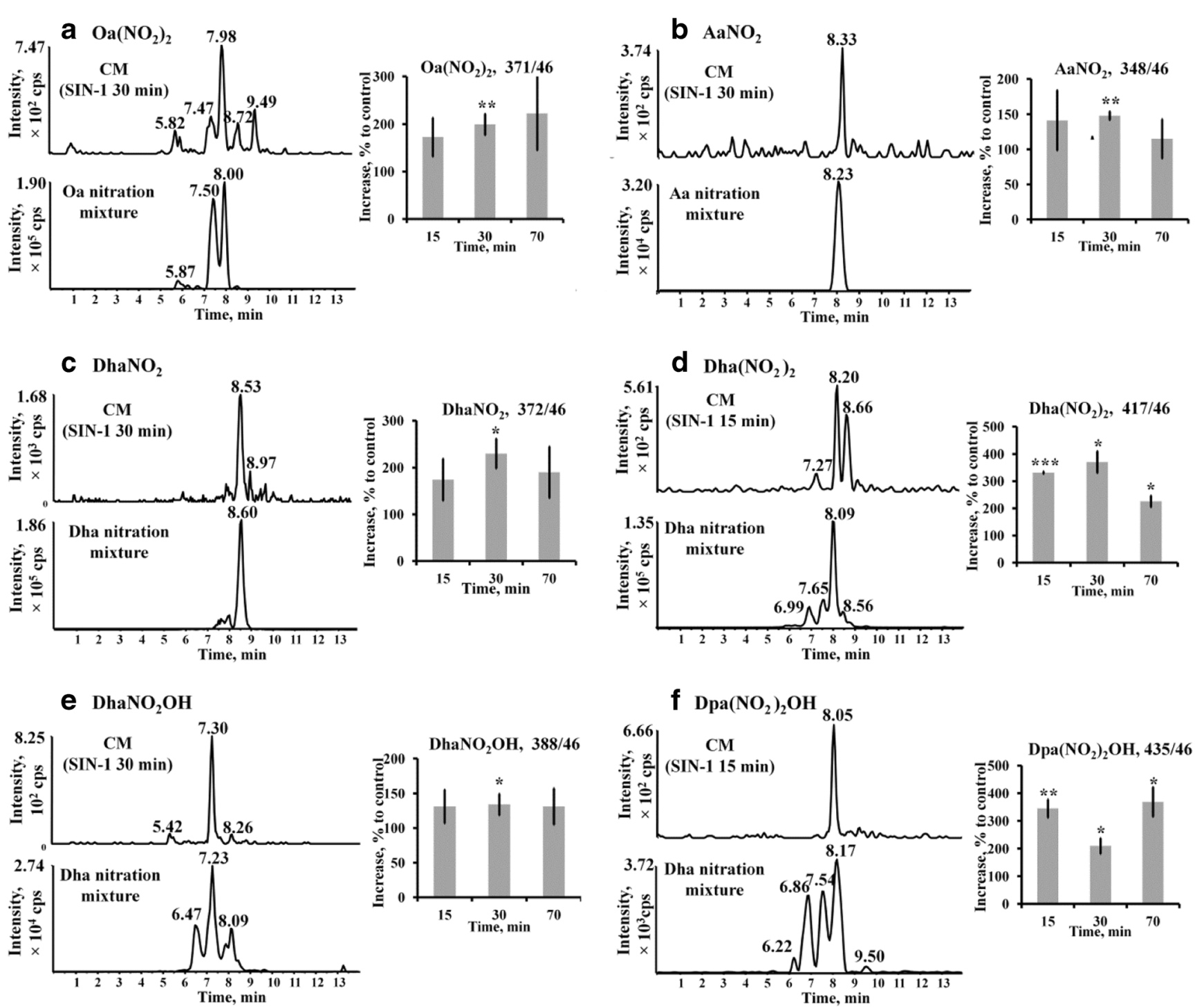

Fig. 4 Extracted ion chromatograms for the quadrupole 1/quadrupole 3 transition pairs corresponding to a $\mathrm{Oa}\left(\mathrm{NO}_{2}\right)_{2}$, b $\mathrm{AaNO}_{2}, \mathbf{c} \mathrm{DhaNO}_{2}$, d $\mathrm{DhaNO}_{2} \mathrm{OH}$, e Dha $\left(\mathrm{NO}_{2}\right)_{2}$, and $\mathbf{f} \mathrm{Dpa}\left(\mathrm{NO}_{2}\right)_{2} \mathrm{OH}$ in cardiomyocyte $(\mathrm{CM})$ lipid extract (upper panels) and corresponding polyunsaturated fatty acids in in vitro nitration mixtures (lower panels). Identification of modified fatty acids was based on the compound-specific MRM transitions and retention times. Measured values were normalized to the values for the

The presence of the endogenously formed $\mathrm{NO}_{2}$-FA was reported for the first time more than a decade ago [9]. Several LC-MS/MS and gas chromatography-MS/MS studies have been directed toward quantification of $\mathrm{LaNO}_{2}$ and $\mathrm{OaNO}_{2}$ in human blood plasma, and reported values between $300 \mathrm{pmol} / \mathrm{L}[9-11,13]$ and $600 \mathrm{nmol} / \mathrm{L}[14,15]$, whereas $\mathrm{AaNO}_{2}$ remained undetected [10]. Recently, Bonnaci et al. [12] showed that dietary cLa rather than bisallylic La is a preferential substrate for the nitration by $\mathrm{ONOO}^{-}$and ${ }^{~} \mathrm{NO}_{2}$, with endogenous levels 0.3 to $1.3 \mathrm{nmol} / \mathrm{L}$ in healthy human plasma. In the present study, we did not observe detectable levels of $\mathrm{LaNO}_{2}, \mathrm{cLaNO}_{2}$, and $\mathrm{OaNO}_{2}$ in control and SIN-1treated rat cardiomyocytes, most probably owing to the low

corresponding controls (100\%), averaged, and represented as bar plots with standard errors. The data represent the mean value of up to five independent measurements. Significant increase in quantified values [control vs 3-morpholinosydnonimine $(S I N-1)$-treated cells] was assigned using a $t$ test (one asterisk $p<0.05$, two asterisks $p<0.01$, three asterisks $p<0.005$ )

concentrations and/or absence of cLa as a nitration substrate in the cell culture medium. Additionally, nitroalkylation of proteins and glutathione by the electrophilic $\mathrm{NO}_{2}$-FA and fatty acid metabolism can reduce endogenous levels of free $\mathrm{NO}_{2}$ FA [43]. Over the past two decades various techniques have been designed for the enrichment of the low endogenous concentrations of Aa-derived $\mathrm{F}_{2}$-isporostanes (approximately $10^{2}$ $\mathrm{pmol} / \mathrm{L}$ in healthy human plasma) from various biological samples [44], and now ensure their routine detection and quantification by LC-MS. Biological concentrations of isoprostanes are similar to those of $\mathrm{NO}_{2}-\mathrm{FA}$ in healthy human plasma; thus, further development of $\mathrm{NO}_{2}$-FA enrichment protocols could improve their detection in biological samples. 
In the present study, Dha-derived nitration products were detected for the first time. Although $\mathrm{F}_{4}$-neuroprostanes derived from $\mathrm{Dha}$, like Aa derived $\mathrm{F}_{2}$-isoprostanes, have been related to various cardiovascular and neurodegenerative disorders $[45,46]$, here we can only speculate about the beneficial effects of Dha-derived nitration products, as was shown for $\mathrm{AaNO}_{2}$ [27, 31, 32] and all other singly nitrated fatty acids. Lipid peroxidation products usually posses proinflammatory properties [47]; however current data on biological activities of $\mathrm{NO}_{2}$-FA support their anti-inflammatory effects via both cGMPdependent and cGMP-independent mechanisms. Although the overproduction of $\mathrm{NO}_{2}-\mathrm{FA}$ was observed during inflammation, a series of anti-inflammatory effects were reported for $\mathrm{LaNO}_{2}[48-50], \mathrm{OaNO}_{2}[15,24]$, and $\mathrm{AaNO}_{2}[27,31,32]$. The question about biological activities of multiply nitrated and nitro-oxidized PUFA remains open owing to the lack of the data on their biological availability.

\section{Conclusion}

A novel analytical approach to explore the diversity of $\mathrm{NO}_{2}$-FA was developed using in vitro nitration mixtures of $\mathrm{Oa}, \mathrm{La}, \mathrm{Aa}$, and Dha for optimization of highly specific and sensitive targeted LC-ESI-MS/MS. Specific MRM transitions were optimized for 42 reaction products - that is, singly and multiply nitrated as well as nitro-oxidized fatty acids. The optimized methods were applied for the detection and relative quantification of $\mathrm{NO}_{2}$-FA in a cardiomyocyte model of nitrosative stress. Six fatty acid nitration products-namely, $\mathrm{Oa}\left(\mathrm{NO}_{2}\right)_{2}$, $\mathrm{AaNO}_{2}, \mathrm{DhaNO}_{2}, \mathrm{Dha}\left(\mathrm{NO}_{2}\right)_{2}, \mathrm{DhaNO}_{2} \mathrm{OH}$, and $\mathrm{Dpa}\left(\mathrm{NO}_{2}\right)_{2} \mathrm{OH}$-were detected and quantified over a period of $70 \mathrm{~min}$ after stress induction, providing the kinetics of $\mathrm{NO}_{2}$-FA formed in cells during nitrosative stress.

\begin{abstract}
Acknowledgments The authors are grateful to Ralf Hoffmann (Institute of Bioanalytical Chemistry, University of Leipzig) for providing access to his laboratories and instruments. Financial support from the European Regional Development Fund (European Union and the Free State of Saxony; 100146238 and 100121468 to M.F.) and a stipend to I.M. provided by Universität Leipzig are gratefully acknowledged.
\end{abstract}

\footnotetext{
Authors' contributions I.M. performed all experimental work, corresponding data evaluation, and contributed to the writing of the manuscript. E.G. and V.V. designed the cell model of nitrosative stress and performed cell culture experiments. N.I., H.N., and N.M. provided the peroxynitrite donor 2,3,5,6-tetramethyl-4-(methylnitrosoamino)phenol. J.M.G., C.O., and T.D. provided internal standards used for liquid chromatography-tandem mass pectrometry. M.F. conceived and designed all experiments and contributed to the writing of the manuscript.
}

\section{References}

1. Pacher P, Beckman JS, Liaudet L (2007) Nitric oxide and peroxynitrite in health and disease. Physiol Rev 87(1):315-424

2. Wink DA, Hines HB, Cheng RYS, Switzer CH, Flores-Santana W, Vitek MP, Ridnour LA, Colton CA (2011) Nitric oxide and redox mechanisms in the immune response. J Leukoc Biol 89(6):873-891

3. Wang GR, Zhu Y, Halushka PV, Lincoln TM, Mendelsohn ME (1998) Mechanism of platelet inhibition by nitric oxide: in vivo phosphorylation of thromboxane receptor by cyclic GMP-dependent protein kinase. Proc Natl Acad Sci U S A 95(9):4888-4893

4. Riddell DR, Owen JS (1999) Nitric oxide and platelet aggregation. Vitam Horm 57:25-48

5. Kubes P, Suzuki M, Granger DN (1991) Nitric oxide: an endogenous modulator of leukocyte adhesion. Proc Natl Acad Sci U S A 88(11):4651-4655

6. Bloodsworth A, O'Donnell VB, Freeman BA (2000) Nitric oxide regulation of free radical- and enzyme-mediated lipid and lipoprotein oxidation. Arterioscler Thrombn Vasc Biol 20(7):1707-1715

7. Liu X, Miller MJ, Joshi MS, Thomas DD, Lancaster JR Jr (1998) Accelerated reaction of nitric oxide with $\mathrm{O} 2$ within the hydrophobic interior of biological membranes. Proc Natl Acad Sci U S A 95(5): 2175-2179

8. Moller MN, Li Q, Vitturi DA, Robinson JM, Lancaster JR Jr, Denicola A (2007) Membrane "lens" effect: focusing the formation of reactive nitrogen oxides from the $\mathrm{NO} / \mathrm{O}_{2}$ reaction. Chem Res Toxicol 20(4):709-714

9. Lima ES, Di Mascio P, Rubbo H, Abdalla DS (2002) Characterization of linoleic acid nitration in human blood plasma by mass spectrometry. Biochemistry 41(34):10717-10722

10. Tsikas D, Zoerner AA, Mitschke A, Gutzki FM (2009) Nitro-fatty acids occur in human plasma in the picomolar range: a targeted nitro-lipidomics GC-MS/MS study. Lipids 44(9):855-865

11. Trettin A, Bohmer A, Zoerner AA, Gutzki FM, Jordan J, Tsikas D (2014) GC-MS/MS and LC-MS/MS studies on unlabelled and deuterium-labelled oleic acid (C18:1) reactions with peroxynitrite $(\mathrm{O}=\mathrm{N}-\mathrm{O}-\mathrm{O}(-))$ in buffer and hemolysate support the $\mathrm{pM} / \mathrm{nM}$-range of nitro-oleic acids in human plasma. J Chromatogr B Anal Technol Biomed Life Sci 964:172-179

12. Bonacci G, Baker PR, Salvatore SR, Shores D, Khoo NK, Koenitzer JR, Vitturi DA, Woodcock SR, Golin-Bisello F, Cole MP, Watkins S, St Croix C, Batthyany CI, Freeman BA, Schopfer FJ (2012) Conjugated linoleic acid is a preferential substrate for fatty acid nitration. J Biol Chem 287(53):44071-44082

13. Tsikas D, Zoerner A, Mitschke A, Homsi Y, Gutzki FM, Jordan J (2009) Specific GC-MS/MS stable-isotope dilution methodology for free 9- and 10-nitro-oleic acid in human plasma challenges previous LC-MS/MS reports. J Chromatogr B Anal Technol Biomed Life Sci 877(26):2895-2908

14. Baker PR, Schopfer FJ, Sweeney S, Freeman BA (2004) Red cell membrane and plasma linoleic acid nitration products: synthesis, clinical identification, and quantitation. Proc Natl Acad Sci U S A 101(32):11577-11582

15. Baker PR, Lin Y, Schopfer FJ, Woodcock SR, Groeger AL, Batthyany C, Sweeney S, Long MH, Iles KE, Baker LM, Branchaud BP, Chen YE, Freeman BA (2005) Fatty acid transduction of nitric oxide signaling: multiple nitrated unsaturated fatty acid derivatives exist in human blood and urine and serve as endogenous peroxisome proliferator-activated receptor ligands. J Biol Chem 280(51):42464-42475

16. Salvatore SR, Vitturi DA, Baker PR, Bonacci G, Koenitzer JR, Woodcock SR, Freeman BA, Schopfer FJ (2013) Characterization and quantification of endogenous fatty acid nitroalkene metabolites in human urine. J Lipid Res 54(7):1998-2009 
17. Ferreira AM, Ferrari MI, Trostchansky A, Batthyany C, Souza JM, Alvarez MN, Lopez GV, Baker PR, Schopfer FJ, O'Donnell V, Freeman BA, Rubbo H (2009) Macrophage activation induces formation of the anti-inflammatory lipid cholesteryl-nitrolinoleate. Biochem J 417(1):223-234

18. Nadtochiy SM, Baker PR, Freeman BA, Brookes PS (2009) Mitochondrial nitroalkene formation and mild uncoupling in ischaemic preconditioning: implications for cardioprotection. Cardiovasc Res 82(2):333-340

19. Khoo NK, Freeman BA (2010) Electrophilic nitro-fatty acids: antiinflammatory mediators in the vascular compartment. Curr Opin Pharmacol 10(2):179-184

20. Rubbo H (2013) Nitro-fatty acids: novel anti-inflammatory lipid mediators. Braz J Med Biol Res 46(9):728-734

21. Freeman BA, Baker PR, Schopfer FJ, Woodcock SR, Napolitano A, d'Ischia M (2008) Nitro-fatty acid formation and signaling. J Biol Chem 283(23):15515-15519

22. Ferreira AM, Minarrieta L, Lamas Bervejillo M, Rubbo H (2012) Nitro-fatty acids as novel electrophilic ligands for peroxisome proliferator-activated receptors. Free Radic Biol Med 53(9): 1654-1663

23. Li Y, Paonessa JD, Zhang Y (2012) Mechanism of chemical activation of Nrf2. PLoS ONE 7(4), e35122

24. Kansanen E, Bonacci G, Schopfer FJ, Kuosmanen SM, Tong KI, Leinonen H, Woodcock SR, Yamamoto M, Carlberg C, YlaHerttuala S, Freeman BA, Levonen AL (2011) Electrophilic nitrofatty acids activate NRF2 by a KEAP1 cysteine 151-independent mechanism. J Biol Chem 286(16):14019-14027

25. Wright MM, Schopfer FJ, Baker PR, Vidyasagar V, Powell P, Chumley P, Iles KE, Freeman BA, Agarwal A (2006) Fatty acid transduction of nitric oxide signaling: nitrolinoleic acid potently activates endothelial heme oxygenase 1 expression. Proc Natl Acad Sci U S A 103(11):4299-4304

26. Trostchansky A, Bonilla L, Thomas CP, O'Donnell VB, Marnett LJ, Radi R, Rubbo H (2011) Nitroarachidonic acid, a novel peroxidase inhibitor of prostaglandin endoperoxide $\mathrm{H}$ synthases 1 and 2. J Biol Chem 286(15):12891-12900

27. Gonzalez-Perilli L, Alvarez MN, Prolo C, Radi R, Rubbo H, Trostchansky A (2013) Nitroarachidonic acid prevents NADPH oxidase assembly and superoxide radical production in activated macrophages. Free Radic Biol Med 58:126-133

28. Klinke A, Moller A, Pekarova M, Ravekes T, Friedrichs K, Berlin M, Scheu KM, Kubala L, Kolarova H, Ambrozova G, Schermuly RT, Woodcock SR, Freeman BA, Rosenkranz S, Baldus S, Rudolph V, Rudolph TK (2014) Protective effects of 10-nitro-oleic acid in a hypoxia-induced murine model of pulmonary hypertension. Am J Respir Cell Mol Biol 51(1):155-162

29. Rudolph TK, Rudolph V, Edreira MM, Cole MP, Bonacci G, Schopfer FJ, Woodcock SR, Franek A, Pekarova M, Khoo NKH, Hasty AH, Baldus S, Freeman BA (2010) Nitro-fatty acids reduce atherosclerosis in apolipoprotein E-deficient mice. Arterioscler Thromb Vasc Biol 30(5):938-945

30. Zheng R, Heck DE, Black AT, Gow A, Laskin DL, Laskin JD (2014) Regulation of keratinocyte expression of stress proteins and antioxidants by the electrophilic nitrofatty acids 9- and 10nitrooleic acid. Free Radic Bol Med 67:1-9

31. Trostchansky A, Souza JM, Ferreira A, Ferrari M, Blanco F, Trujillo M, Castro D, Cerecetto H, Baker PR, O'Donnell VB, Rubbo H (2007) Synthesis, isomer characterization, and antiinflammatory properties of nitroarachidonate. Biochemistry 46(15):4645-4653
32. Bonilla L, O'Donnell VB, Clark SR, Rubbo H, Trostchansky A (2013) Regulation of protein kinase $C$ by nitroarachidonic acid: impact on human platelet activation. Arch Biochem Biophys 533(1-2):55-61

33. Ieda N, Nakagawa H, Peng T, Yang D, Suzuki T, Miyata N (2012) Photocontrollable peroxynitrite generator based on N-methyl-Nnitrosoaminophenol for cellular application. J Am Chem Soc 134(5):2563-2568

34. Guy A, Oger C, Heppekausen J, Signorini C, De Felice C, Furstner A, Durand T, Galano JM (2014) Oxygenated metabolites of n-3 polyunsaturated fatty acids as potential oxidative stress biomarkers: total synthesis of $8-\mathrm{F}_{3 \mathrm{t}}-\mathrm{IsoP}, 10-\mathrm{F}_{4 \mathrm{t}}-$ NeuroP and $\left[\mathrm{D}_{4}\right]-10-\mathrm{F}_{4 \mathrm{t}^{-}}$ NeuroP. Chemistry 20(21):6374-6380

35. Oger C, Bultel-Ponce V, Guy A, Balas L, Rossi JC, Durand T, Galano JM (2010) The handy use of Brown's P2-Ni catalyst for a skipped diyne deuteration: application to the synthesis of a $\left[\mathrm{D}_{4}\right]-$ labeled $\mathrm{F}_{4 \mathrm{t}}$-neuroprostane. Chemistry 16(47):13976-13980

36. Matyash V, Liebisch G, Kurzchalia TV, Shevchenko A, Schwudke D (2008) Lipid extraction by methyl-tert-butyl ether for highthroughput lipidomics. J Lipid Res 49(5):1137-1146

37. Bonacci G, Asciutto EK, Woodcock SR, Salvatore SR, Freeman BA, Schopfer FJ (2011) Gas-phase fragmentation analysis of nitrofatty acids. J Am Soc Mass Spectrom 22(9):1534-1551

38. Woodcock SR, Bonacci G, Gelhaus SL, Schopfer FJ (2013) Nitrated fatty acids: synthesis and measurement. Free Radic Biol Med 59:14-26

39. Halliwell B, Gutteridge JMC (1999) Free radicals in biology and medicine, 3rd edn. Clarendon Press, Oxford

40. Huie RE (1994) The reaction kinetics of $\mathrm{NO}_{2}$. Toxicology 89(3): 193-216

41. Jezek J, Jaburek M, Zelenka J, Jezek P (2010) Mitochondrial phospholipase A2 activated by reactive oxygen species in heart mitochondria induces mild uncoupling. Physiol Res 59(5):737-747

42. Rashba-Step J, Tatoyan A, Duncan R, Ann D, Pushpa-Rehka TR, Sevanian A (1997) Phospholipid peroxidation induces cytosolic phospholipase A2 activity: membrane effects versus enzyme phosphorylation. Arch Biochem Biophys 343(1):44-54

43. Tsikas D, Zoerner AA, Jordan J (2011) Oxidized and nitrated oleic acid in biological systems: analysis by GC-MS/MS and LC-MS/ MS, and biological significance. Biochim Biophys Acta 1811(11): 694-705

44. Milne GL, Musiek ES, Morrow JD (2005) F2-isoprostanes as markers of oxidative stress in vivo: an overview. Biomarkers 10(Suppl 1):S10-S23

45. Montuschi P, Barnes PJ, Roberts LJ (2004) Isoprostanes: markers and mediators of oxidative stress. FASEB J 18(15):1791-1800

46. Ricciotti E, FitzGerald GA (2011) Prostaglandins and Inflammation. Arterioscler Thromb Vasc Biol 31(5):986-1000

47. Lee SE, Park YS (2013) Role of lipid peroxidation-derived $\alpha$, $\beta$ unsaturated aldehydes in vascular dysfunction. Oxid Med Cell Longev 2013:629028

48. Lim DG, Sweeney S, Bloodsworth A, White CR, Chumley PH, Krishna NR, Schopfer F, O'Donnell VB, Eiserich JP, Freeman BA (2002) Nitrolinoleate, a nitric oxide-derived mediator of cell function: synthesis, characterization, and vasomotor activity. Proc Natl Acad Sci U S A 99(25):15941-15946

49. Coles B, Bloodsworth A, Eiserich JP, Coffey MJ, McLoughlin RM, Giddings JC, Lewis MJ, Haslam RJ, Freeman BA, O'Donnell VB (2002) Nitrolinoleate inhibits platelet activation by attenuating calcium mobilization and inducing phosphorylation of vasodilatorstimulated phosphoprotein through elevation of cAMP. J Biol Chem 277(8):5832-5840 
50. Coles B, Bloodsworth A, Clark SR, Lewis MJ, Cross AR, Freeman BA, O'Donnell VB (2002) Nitrolinoleate inhibits superoxide generation, degranulation, and integrin expression by human neutrophils: novel antiinflammatory properties of nitric oxide-derived reactive species in vascular cells. Circ Res 91(5):375-381

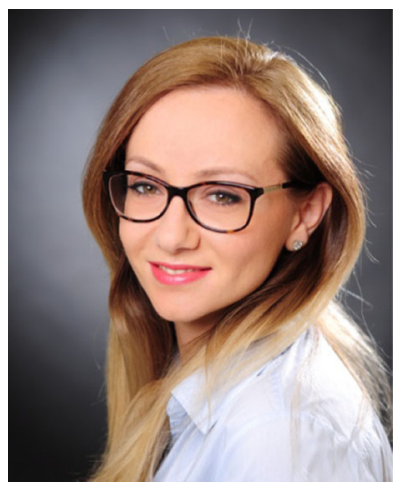

Ivana Milic is a $\mathrm{PhD}$ candidate in the Institute of Bioanalytical Chemistry, Faculty of Chemistry and Mineralogy, at the University of Leipzig. Her research is focused on the development of liquid chromatography-mass spectrometry-based protocols for analysis of oxidized lipids and lipid-protein adducts.

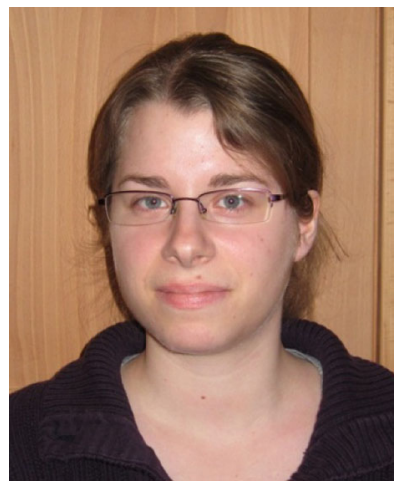

Eva Griesser is a $\mathrm{PhD}$ candidate in the Institute of Bioanalytical Chemistry, Faculty of Chemistry and Mineralogy, at the University of Leipzig. Her research is focused on protein and lipid modifications in various cellular models of oxidative stress.

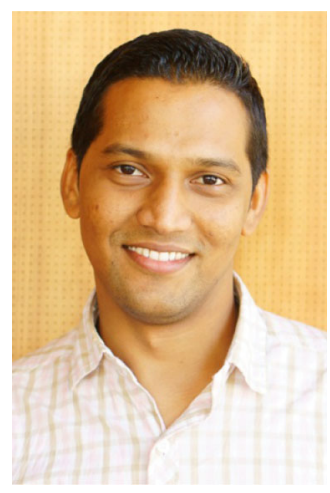

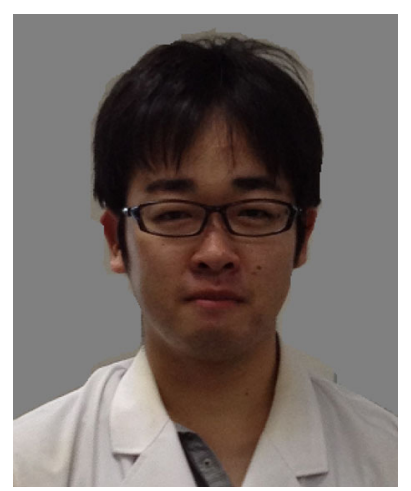

Naoya Ieda is an assistant professor of organic and medicinal chemistry in the Graduate School of Pharmaceutical Sciences, Nagoya City University. He has been working for several years on the development of photocontrollable reactive nitrogen species releasers as biological research tools or novel photodynamic therapy drug candidates.

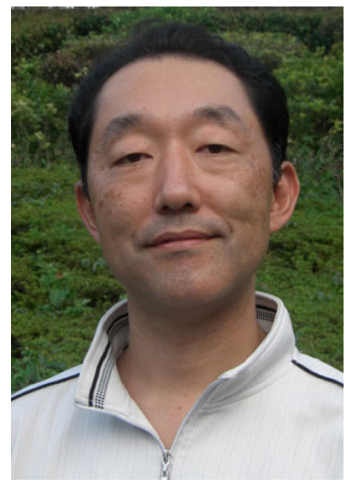

Hidehiko Nakagawa is Head of the Laboratory of Organic and Medicinal Chemistry, Graduate School of Pharmaceutical Sciences, Nagoya City University. He has been working on the development of photocontrollable $\mathrm{NO}$ and related reactive nitrogen species, as well as the development of chemical tools for medicinal chemistry.

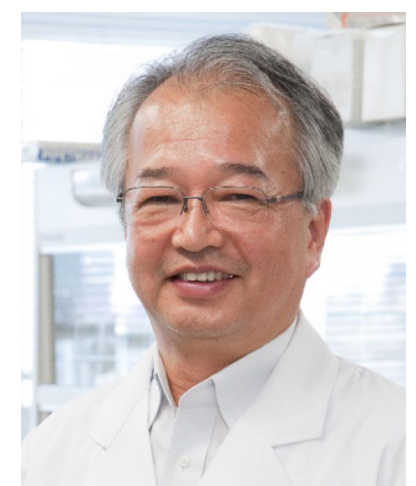

Naoki Miyata is a professor in the Institute of Drug Discovery Science of the Graduate School of Pharmaceutical Sciences, Nagoya City University. His research interests are chemical biology focused on reactive oxygen species and reactive nitrogen species, and also medicinal chemistry to develop useful enzyme inhibitors for the treatment of cancer and neurodegenerative disorders. His research is always based on organic chemistry. 


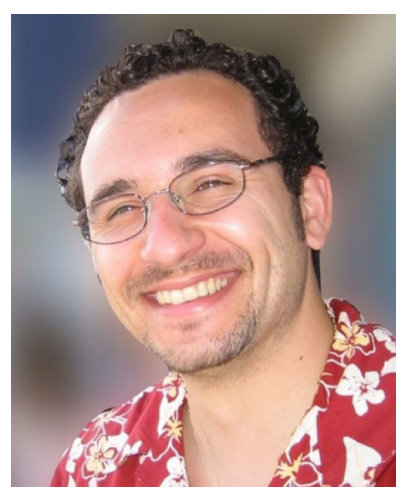

Jean-Marie Galano studied chemistry at Paul Cézanne Université Marseille and obtained his $\mathrm{PhD}$ degree in the field of total synthesis under the supervision of Honoré Monti in 2001. He then moved to the University of Oxford to pursue a postdoctoral fellowship with David H. Hodgson on the development of new methods for the total synthesis of natural products. In October 2005 he joined the CNRS as a chargé de recherche at the University of Montpellier. His research focuses on new methods and strategies toward the total synthesis of natural products.

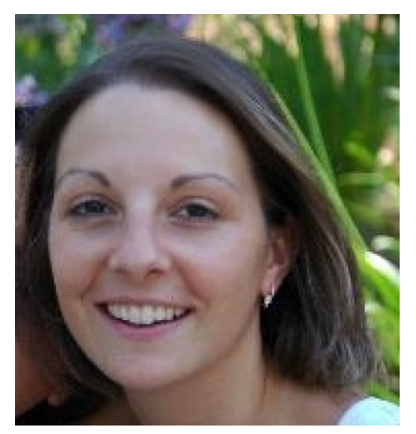

Camille Oger obtained her $\mathrm{PhD}$ degree in organic synthesis in 2010 and is currently an assistant professor in organic chemistry in the University of Montpellier. Her research mainly focuses on the synthesis of lipid metabolites and their identification/quantitation in biological fluids as well as the discovery of biological properties.

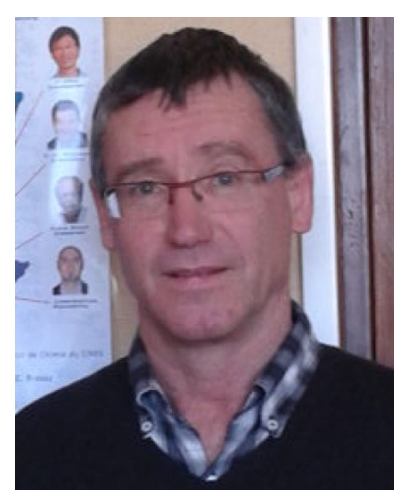

Thierry Durand is a group leader at the Institute of Biomolécules Max Mousseron. His research interests include the total synthesis of oxygenated cyclic and noncyclic metabolites of polyunsaturated fatty acids, mainly leukotrienes, isoprostanes, phytoprostanes, and neuroprostanes, as well as dihydroxylated polyunsaturated fatty acids, and the understanding of the role of such bioactive lipids by developing collaborations with chemists, biochemists, biologists, and clinicians all over the word.

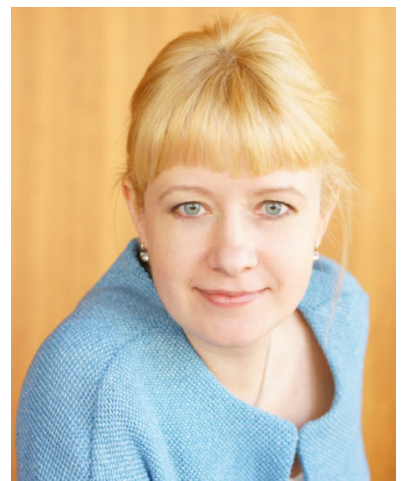

Maria Fedorova is a group leader in the Institute of Bioanalytical Chemistry, Faculty of Chemistry and Mineralogy, at the University of Leipzig. Her research is focused on analysis of oxidized lipids and proteins as well as lipid-protein adducts in variety of in vitro and in vivo systems. 